\title{
ERERGETIC-NEUTRON SFECTROMETRY
}

Arnual Progress Regort

for the period from

1 April 1973 to 31 March 1974

Fichard Madey, Frank M. Waterman, and Alan Baldwin

Kent State Untversity

Kent, On10 44242

Frepared for the U.S. Atante Energy Commission

under Contract No. AT(11-1)-2232

Principal Investigator: Richard Madey

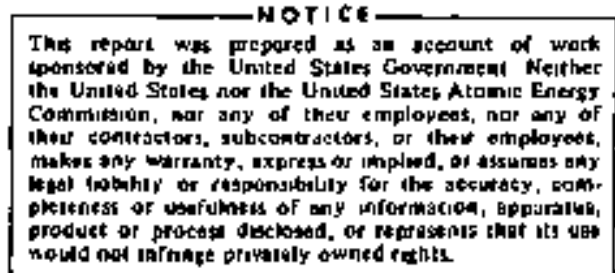

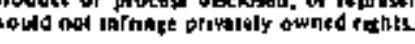




\section{DISCLAIMER}

This report was prepared as an account of work sponsored by an agency of the United States Government. Neither the United States Government nor any agency Thereot, nor any of their employees, makes any warranty, express or implied, or assumes any legal liability or responsibility for the accuracy, completeness, or usefulness of any information, apparatus, product, or process disclosed, or represents that its use would not infringe privately owned rights. Reference herein to any specific commercial product, process, or service by trade name, trademark, manufacturer, or otherwise does not necessarily constitute or imply its endorsement, recommendation, or favoring by the United States Government or any agency thereof. The views and opinions of authors expressed herein do not necessarlly state or reflect those of the United States Government or any agency thereof. 


\section{DISCLAIMER}

Portions of this document may be illegible in electronic image products. Images are produced from the best available original document. 
1. Introduction - 1

2. Research Accomplistments 4

3. Activities in Progress 10

4. Contract Compliance 12

5. B1bulography 13

6. References 16

APFENDICES

A. Experimental Confimation of the Principles of the Two-Parameter Measurenent Technique.

B. Development of the Two-Parameter Spectrometer.

c. The On-Line Data Acquisition Syster.

D. Measurement of a Simulated Omidirection Neutron Spectrum with the Two-Parameter Spectrometer. 
ABSTRACT

Initial steps have been taken to modify a self-contained time-of-fllght spectroneter for unidirectional neutrons in order to extend its capability to measure omidirectionally incident neutrons. To measure the spectrum of ormidirectionally incident neutrons, it is necessary to measure two parameters, namely, the energy of the recoil-proton in the first detector in addition to the energy of the scattered neutron. The princtple of the two-paremeter measurement technique was canfirmed in a measurement of the neturon spectrum produced at $0^{\circ}$ from $71-\mathrm{MeV}$ deuteron bombartment of a thick carbon target at the University of Maryland cyclotron. This measurement established also an improved techrique for subtracting backgrounds in untdirectional spectral measurenents. To measure conidirectionally inctient neutrons from 5 to about $150 \mathrm{MeV}$, it was necessary to design and construct an Improved ifnegr gate and stretcher with a potential dynantc range of 600 to 1 , to design and procure a large $10 \mathrm{tn}$. by $10 \mathrm{in.} \mathrm{by} 4 \mathrm{in.} \mathrm{(ND-102} \mathrm{plast1c)} \mathrm{first}$ detector, and to design and construct a $10 \mathrm{tn}$. by $10 \mathrm{in}$. by $4 \mathrm{in}$. alunfum chamber for encapsulating the $\mathrm{NE}-226$ Ifquid first detector. The ablitty of the spectroneter to measure ontidirectionally incident neutrons was tested in a simulated omidirectiona) spectral measurement at the Unitersity of Iaryland eyclotron ustng the neutron beam produced at $0^{\circ}$ from $82-p h=V$ deuteron bombardment of a thick beryllium target. To similate a spectral meazurement of cmidirectional neutrons, measurements were made with the neutron 
beam incident on the spectrometer at angles of $20^{\circ}, 45^{\circ}$, and $75^{\circ}$.

These data are presently belng analyzed. 


\section{Introduction}

This report describes progress made during the past year under Contract No. AT(11-1)-2231 with Kent State University. The overall objectives of this program are the developnent of a spectroneter for measurement of neutrons in the energy region from a few MeV to several hundred ifeV and the measurement of energetic-neutron spectra at particle accelerators. Previously, Kadey and Waterman (1973 a,b, 1974) and Waterman and Hadey (1973) have developed the spectroneter to measure. the spectrum of neutrons incident: unddrectionslly on the spectrometer over, the enem region from about $1 \mathrm{MeV}$ to $1 \mathrm{GeV}$ and have used-the spectrometer: to:measure thick and thin target neutron spectra at particle accelerators.

In addition to continuing needs for measurements of undirectional neutron spectra, a need exlsts also for an Instrument system that can determine the flux and energy spectrum of omidirectional neutron radiation in the energy region from a fev lieV to a few hundred Mev. The need for such an instrument arises in connection with accelerator radiation dosinetry and shfelding measurements involving the transport of energetfc-neutrons. - . . . : . - is

The spectrometer developed previously for measuring unidirect1onal neutron spectra measures a single parameter, namely, the time-of-flight of a neutron scattered between two seintillation counters. To measure the spectrm of omidirectionally incident 
neutrons, it is necessary to measure two paraneters, namely, the energy of the recoil-protion in the first detector in addition to the energy of the scattered neutron. During the past year, we have made progress in extending the applicability of the spectrometer to the measurement of omidirectionaily incident neutrons. Our intial objective is to develop the spectrometer for measurement of the neutron skyshine and skyshine source spectra at the Erbokhaven Alternat1ng Gradient Symchrotron * (AGS): $\therefore$. The-: results of the skyshtne measurenents will be used to develop a skyshine transport todel of general applicabillty for accelerators. We will colleborate with Dr. R.G. Alsmiller, Jr. at the Cak R1dge National Laboratory and Mr. Carl Distenfeld at the Brookhaven National Laboratory in the interpretation of the skyshine measurements.

Our research accomplishments during the past year can be classified into the following categories:

a. Experimental confirmation of the principle of the twoparameter measurement techrique.

b. Establishnent of an improved techrique for subtracting backgrounds in unldrectional neutron spectal measurements.

c. Design and construction of a linear gate and stretcher with a large dynanic range.

di Design, procurement, and construction of large scintillation counters for neutron slosiline measurements. 
e. Spectfication, procurement, and test of a transportable on-Ine data acquistition system.

f. Measurement of a simulated omidirectional neutron spectrmm with the two-parameter spectrometer.

g. Peasurement of neutron spectra of interest for neutron radiotherapy and neutron irradiation studies of biological systems.

h. Prelininary design study for an on-line data acquisition system at LANPF.

1. Preliminary thin tanget measurements at the Univergity of Maryland.

j. Presentations at scientific metings.

k. Papers published during the past year.

The specific accomplishments in each of these categories are described in Section 2. 
2. Research Accomplishiments

our research accomplishments during the past year are summanized below.

a. Experfinental Confinmation of the Principle of the

Two-Parameter Measurement Technique

In July 2973, we set up a two-parameter spectrometer at the University of Maryland cyclotron and measured the neutron spectrum at $0^{\circ}$ from $71-\mathrm{kbV}$ deuteron bonbardment of a thick carbon target. The dynamile range of the recoll-proton energtes that could be measured was limited by the available apparatus to a ratio of about 5 to 1. Since the neutron beam was unidirectional, it was possible to analyze the data by both one-and two-parameter techniques. The one-parameter measurement, which has been proven, served as a standand for conparison of the two-parameter measurement. Agrement of the results obtained by the one-end two-parameter analysis techniques confins the principle of the two-pargmeter spectroneter. Append1x $A$ is a detailed description of this experdment.

b. Establishment of an Improved Techntgue for Subtracting Hackgrounds in thairectional Neutron Spectral Measurements

We have established an improved technique for subtracting carbon beckground from spectral measurenents of neutrons incident 
inidirectionally on the two-paraneter spectrameter. Previously, we have determined carton background from separate spectral measurements with $\mathrm{NE}-102$ and NE-228 first detectors in the manner described by Madey and Wateman (1973a). A principal advantage of the Improved technigue is that only one spectral measurement is required with either scintillator type. Also, the carbon subtraction technique employtng separate spectral measurements with RE-102 and NE-228 first detectors degrades the stat1stical uncertainty in the measurement by about a factor of 2 whereas the Improved technique does not. Another advantage of the carbon subtraction technique with the two-paraneter spectrometer is that it rejects also a major fraction of the background from the accidental cofncidences that decur in the measurements with the one-paraneter spectrometer; thus, the two-parameter spectrometer can measure unfdifrectional neutrons in a bigher background enviroment or from an accelerator with a poorer duty cycle than possible previously with the oneparameter spectroneter. This Inproved technique is described in Section 4 of Appendix A.

\section{c. Desien and Construction of a Whear Gate and Stretcher With a Large Dynamic Range}

Commercially available linear gate and stretchers do not have a dymamic range adequate to measure the recoll-proton pulse-height spectrum in an cmidinectional spectral measurement 
over the neutron energy region from a few MeV to about $150 \mathrm{MeV}$. Such a measurement requfres the capability to measure recoll proton energles over the region from about $1 \mathrm{MeV}$ to $150 \mathrm{MeV}$. In NE-102 plastic scintillator, recoli-proton energles of 1 and $150 \mathrm{meV}$ give a light output equivalent to $0.75 \mathrm{MeV}$ and $125 \mathrm{meV}$ electrons, respectively; bence, the dynaric range of the recoll-proton pulse nelght spectrion is about 170 to 1. A Hnear gate and stretcher module has been designed and constructed for this purpose that is linear for photormultiplier anode pulses from 25 millivolts to 15 volts, thus giving a potential dymanic range of 600 to 1 . The development of this improved linear gate and stretcher is described in Appendix $B$.

a. Design, Procurement, and Constimuction of Large Sc1ntillation Counters for Neutron Skyshine Measurements

A large $10 \mathrm{~m}$. by $20 \mathrm{in}$. by $4 \mathrm{in}$. thick $\mathrm{NE}-102$ plastic scintillation counter was designed, procured, and tested for the measurement of neutron skyshine at the Brockhaven Altemating Gradient Synchrotron. This scintillator was used successfully in a simulated omidirectional neutron spectral measurement at the iniversity of Maryland cyclotron in March 1974. An aluminum .. chamber for encapsulatting a $10 \mathrm{fn}$. by $10 \mathrm{1n}$. by 4 in. thick NE-228 liquid scintillator has been designed and constructed at Kent State University. This aluminum chamber is designed so that the liquid scint1llator is in direct contact with the photomultiplier. 
These large scintillators tre described further in Appendix B.

e. Specification, Procurement, and Test of a Transportable On-Ine Data Acquistition System

A transportable on-line data acquisition systen was specifled, procured, and tested. The system consists of a PDP 11/15 conputer and extended memory with a total of $24 \mathrm{~K}$ (16 bit) words of care memory, four analog-to-digital converters, a magnetic tape unlt. and pertpheral equipnent 1ncluding a teletype, live-t1me clock, control panel, and display scope. This system was successfully transported to the University of Maryland for a recent experiment. The on-line data acquisition system is described further in Appendix C.

r. Measurement of a Simizated Omidirectionel Neutron Spectrum w1th the Tho-Paraneter Spectrometer

In March 1974, we tested the two-parameter spectrometer by measuming the neutron spectrum at $0^{\circ}$ from $82 \mathrm{MeV}$ deuteron bombandment of a thick berylifum target at the University of Maryland cyclotron. To sinulate an omidirectional spectral measurement, separate measurements were made with the neutron beam Incident on the spectrometer at angles of $20^{\circ}, 45^{\circ}$, and $70^{\circ}$. These data are presently beling anadyzed. A more detailed description of the technical approach and some preliminary observations are given in Appendix D. 
- . Measurement of Neutron Spectra of Interest for Neutron Radiotherapy and Neutron Irradiation Studies of Biological Systems

Diring the past year, we measured the spectra of netutrons produced at $0^{\circ}$ from $7 \mathrm{l} \mathrm{keV}$ deuteron bombartinent of a thick carbon target and from $82 \mathrm{MeV}$ deuteron bombardment of a thick berylitium target at the Undversity of Maryland cyclotron. Spectral. measurements of these neutron beams are of current interest for potential application in neutron radiotherapy. Dr. Ceorge Harmison at the Und verstty of Maryland Medical School is currently using the cyclotron at College Park to conduct neutron irradiation studies of blological systems. The spectrum obtained from $71 \mathrm{MeV}$ deuteron bombardment of a thick carbon target is shown in Fig. 10 of Appendix A.

\section{n. Prelempinary Desigm Study for an On-Line Data Acquisition} System at LAMPF

A prelintnary design study was made for an on-line spectrometer for monitoring the neutrons generated by the IAMPF beam stop. This design study was stimulated by Los Alamos persomnel, particulariy Dr. Walter Green, at the 1973 Summer Study Group on Practical Applications of Accelerators. Such an on-line monitor is needed for neutron radiation damage stuates to be conducted at LAMPF With neutrons produced in the matn beam stop. This preliminary 
study Indicates that the one-parameter spectrometer developed by Madey and Waterman (1973a) may be usefully applied at LAlPIr. Recent progress indicates that the two-parameter spectrometer may be better suited to monitor the neutrons generated by the LAMPF beam stop. As described in iter (b), the two-parmeter spectroneter can measure unidirectional neutron spectra in a higher backgrourd enviromment of from an accelerator with a poorer duty cycle then possible previously with the one-parameter spectrameter. This advantage is particularly jmportant for applications at IAMPF on account of the poor duty cycle there.

1. Preliminary Thin Target Keasurements at the University of Maryland

A prelininary measurement of the neutron spectrum at $45^{\circ}$ from $100 \mathrm{keV}$ proton bonbardment of a $30 \mathrm{mg} / \mathrm{cm}^{2} \mathrm{N1}^{58}$ target at the thiversity of liaryland cyclotron Indicates that it is feastble to measume neutron spectra from thin targets at this facility.

\section{j. Presentations at Scientific Meetings}

Ritchard Madey and F. N. Waterman, "Heutron Spectronetry from $200 \mathrm{MeV}$ to I GeV', Bull. Am. Phys. Soc. 18, 617 (1973).

Richard Madey and F. H. Watemen, "Neutron Spectral Measuments in the Region from 5 to $724 \mathrm{MeV}, "$ Summer Study Group on Practical Applications of Accelerators, Clinton P. Anderson Meson Physics Facility, 27-31 August 1973.

Walter Green, Edward Krapp, Rlchard Hadey, Tom Blewitt, Donald Cochran, and Dean Oen, Participants in a Round Table Discussion at the Summer Study Group on Practical Applications of Acceleratons, Cltnton P. Anderson Meson 
- Physics Factizty, 27-31 August 1973.

Richard Nadey and F, M. Naterman, "Neutron Spectra at $0^{\circ}$ from $724 \mathrm{MeV}$ Protons on Be and $\mathrm{Cu}, " \mathrm{Bu} 1$. Am. Phys. Soc. 18, $1420(1973)$.

R. Madey, F. M. Watermen, A. Baldwin, and N. S. Wail, "Neutron Spectrum at $0^{\circ}$ from 71 MeV Deuteron Bombardment of a Thick Carbon Target", Bull: An. Phys. Soc. 19, (to be presented at the Pittsburgh meeting, 31 oct.2 Nov. 1974).

k. Papers Published During the Past Year

R. Madey and R. M. Waterman, "Neutron Spectrometry from 1 MeV to $1 \mathrm{CeV}^{*}$, Proceedings of the IAEA SYmosiun on Neutron Monitoring for Ratiation Protection purposes, Vol. I, Viemia, Austria, 11 -15 Decenber 1972, (Interriational Atomic Energy Agency, vienna, 1973) pp. 113-121.

R. Madey and F. M. Waterman, "High-Enerey Neutrons Produced by $740 \mathrm{MeV}$ Protons on Urantum", Physical Revlew C 8 , 2412 (1973).

F. M. Waterman and R. Padey, "Neutron Spectra at $0^{\circ}$ from $724 \mathrm{MeV}$ Protons on Be and Cu", Physical Review C 8, 2419 (1973).

Richard Madey and F. P. Waterman, "A THme-of-F21ght Spectrometer for Neutrons from about $150 \mathrm{MeV}$ to $1 \mathrm{GeV}, "$ Nuclear Instrmants and Methods 114, 483 (1974).

Alan R. Balditin and Richard Madey, "A Useful 350 Megahertz Scaler", Rev. Sc1. Inst. 45,711 (Niay 1974).

\section{Activities in Progress}

Activities in progress include the following:

a. Analysis of data from the March 1974 measurements at the University of Maryiand

(1) Simulated omfdirectional spectrum measurement using the neutron beam at $0^{\circ}$ from $82 \mathrm{MeV}$ deuteron bombardment 
of a thick beryljum target.

(2) Preliminary thin target neutron spectral measurenent.

b. Preparation for experiments at particle accelerators

(1) Measurement of the neutron skyshine and skyshine source spectrum at the Brookhaven AGS.

(2) Measurement of the neutron production from stopped negative plons at the Columbla University Nevis Cyclotron Laboratory.

(3) Jeasurerent of the neutron production from proton bombarment of thick and thin targets at the Untversity of Haryland cyclotron.

c. Preparation of menuscripts for presentation and/or publication

(1) Neutron spectrum at $0^{\circ}$ from $71 \mathrm{keV}$ deuteron bomardment of a thick carbon target.

(2) An Inproved spectrometer for unidirectional neutron spectral measurements in the region from 5 to $150 \mathrm{HeV}$.

a. Studjes of Spectrometer Appltcations

(1) An on-11ne spectrometer for montarting the neutrons generated by the IAIMP beam stop.

(2) Thin and thick target neutrom spectral measurenents at the University of haryland cyclotron.

(3) The leakage neutron spectrum above the Brookhaven 200 liev proton linac water shteld tark. 
4. Contract Compliance

- The principal investigator devoted at least 15 percent of his time during the 1973-1974 academic year and one 1973 surmer session and full-time during another 1973 surmer sesston to the project. To the best of our knowledge, there have been no failures to comply with the contract requfrements. 


\section{Bibliography}

This biblfography lists papers, presertations, preprints, and reports prepared under Contract AT (11-1) - 2231. Reprints of documents c00-2231-I through c00-2231-10 are appended to our progress report (co0-2231-11) for the pertod 1 Apintl 1972 through 31 farch 1973. Feprints of documents c00-2231-12 through $000-2231-21$ are appended to this progress report $(000-2231-21)$.

c00-2231-1

Meutron Spectrometry from $1 \mathrm{NeV}$ to $1 \mathrm{GeV}$, Richard Madey and F.M. Haterman, International Atomic Energy Agency Reprint IAEA/SIM-167/47, IAEA Symposium on Heutron Monitoring for Radiation Protection Purposes, Vlenna, Austria, 11-15 December 1972.

CoO-2231-2

Neutron Spectrometry from $1 \mathrm{l}: \mathrm{eV}$ to $\mathrm{GeV}$, Remarks prepared for presentation on 11 December 1972 by Richard Nadey at the International Atomic Energy Agency Symposlum on Neutron Monitoring for Radiation Protection Purposes at Vienna, Austria.

COO-233I-3

High-Energy Neutrons Produced by $740 \mathrm{MeV}$ Protons on Uranium, Richard Madey and F.M. Waterman, Bull. Ar. Phys, Soc. 17, 581 (April 1972).

$000-2331-4$

High-Energy Neutrons Produced by $740 \mathrm{MeV}$ Protons on Uranium, Remarks prepared for presentation by RIchard Madey at the Washington, D.C., meeting of the American Physical Society on 27 April 1972.

COO-2231-5

High-Energy Neutrons Produced by $740 \mathrm{MeV}$ Protons on Uranium, Remarks prepared for presentation by Richard Madey at a physies colloquium at the Los Alamos Scientifle Laboratory on 4 May 1972, and al:30 at the summer study session for the Indiana University cyclotron Facility at Bolzlder, Colorado, 12-16 June 1972. 
COO-223I-6

The Response of NE-228 Liquid Scintillator to 3.5 , 5.8 , and $10.5 \mathrm{MeV}$ Frotons, P., Tadey and F.F. Waterman, Nuci. Instr. and Meth. 104, 253-256 (1972).

COO-223I-7

A Time-of-Filght Spectrometer for Neutrons from I MeV to $500 \mathrm{MeV}$, Richard Madey and Frank li. Waterman, Nucl. Instr. and Meth. 106, 89-101 (1973).

$600-2331-8$

Neutron spectrometry from 200 iev to $1 \mathrm{GeV}$, Richard Madey and F.M. Waterman, Bull. Am. Phys. Soc. 18 . 617 (April 1973).

$\therefore \quad$ CoO-2231-9

H1gh-Energy Neutrons Produced by $740 \mathrm{MeV}$ Protons on Urantum, Frank M. Waterman, Ph.D. Dissertation Abstract, Clarkson College of Technology (May 1973).

coo-2231-10

A 350 Megahertz Decade Scaler, Alan R, Baldwin and Richard Madey.

$000-2231-11$

Energetic-Neutron Spectrometry, Richard Madey and Frank $M$. Waterman, Progress Report for the period 1 April 1972 through 31 liarch 1973.

coo-2231-12

Neutron spectrometry from $200 \mathrm{MeV}$ to $I \mathrm{GeV}$, Remarks prepared for presentation by k1chard Madey at the Washington, D.C. meeting of the American Physical Society on 24 Apr1I 1973.

c00-2231-13

Neutron Spectral Measurements in the Region from 5 to $724 \mathrm{MeV}$, Richard Madey and P.M. Waterman, Proceedings of the Summer Study Group on Practical Applications of Accelerators, Clinton P.Anderson Meson Physics Facility, 27-31 August 1973 (to be published). 
COO-2231-14

Neutron Spectral pleasurements in the Fegion from 5 to $724 \mathrm{HeV}$, Remarks prepared for presentation by Richard Madey at the Suminer Study Group on Practical Applications of Accelerators, clinton F. Anderson tieson Physics Facility on 31 August 1973 .

c00-2231-15

Neutron spectra at $0^{\circ}$ from $724 \mathrm{MeV}$ Protons on Be and $\mathrm{Cu}$, Rlchard Hadey and F.M. Waterman, Bull. Am. Phys. Soc. 18, $1.420(1973)$.

coo-2231-16

Neutron Spectra at $0^{\circ}$ from $724 \mathrm{MeV}$ Protons on Be and cu, Remarks prepared for presentation by Richerd Madey at the Bloomington, Indiana meeting of the American Physical society on 3 November 1973.

coo-2231-17

Neutron Spectrometry from $1 \mathrm{MeV}$ to $1 \mathrm{GeV}$, R. Madey and F.M. Waterman, Proceedings of the IAEE Symposium on Neutron Monttoring for Radiation Protection Pürposes, Vol. I, Vlenna, Austria, I1-15 December 1972, (International Atomic Energy Agency, V1enna, 1973) pp. 113-121.

C0O-2231-18

High-Energy Neutrons Produced by 740 Mev Protons on Uranium, R.Madey and F,H. Wa terman, Physicel Review C 8,2412 (1973).

COO-223I - 19

Neutron Spectra at $0^{\circ}$ from $724 \mathrm{MeV}$ Protons on Be and $C u, F . M$. Waterman and $R$. Madey, Physical Review $c \mathbb{g}$, 2 मे 2 (1973).

COO-2231-20

A TIme-or-Flight spectrometer for Neutrons from about $150 \mathrm{MeV}$ to 1 GeV, Richard Madey ana Frank M. Waterman, Nuclear Instruments and Methods 114, 483-487 (1974).

$\infty 00-2231-21$

Energetic-Neutron Spectrometry, Richard Madey, Frank M. Waterman, ard Alan Ealdwin, Frogress Peport for the pertod from 1 Adril 1973 to 30 Aprit 1974 


\section{References}

MADEY, R.

1973a: and F. M. Waterman, A Thme-of-Fitight Spectrometer for Neutrons from 1 to $500 \mathrm{MeV}$, Mucl. Instr. and Meth. $106,89$.

1973b: and F. M. Waterman, Hgh-Energy Neutrons Produced by 740-MeV Frotons on Urantum, Phys. Pev, C 8, 2412.

1974: and F. M. Waterman, A rime-of-Flight Spectroneter from about $150 \mathrm{MeV}$ to $1 \mathrm{GeV}$, Nucl. Instr. and Meth. 114, 483.

WATERMAN, F. M.

1973: and R. Hadey, Neutron Spectra at $0^{\circ}$ from 724-MeV Protons on Be and or, Fhys. Fev, C 8, 2419. 
Appendix A

Experimental Confirmation of the Principle

of the Two-Parameter Yeasurement Techntque 
Appencix A

Experimental Confimation of the Principle of the Two-Parameter Measurement Technique .

\section{Introduction}

Madey and Waterman (1973) have described previously a time-offlight spectrometer for measurins uniafrectional neutrons from 1 to $500 \mathrm{MeV}$. This spectrometer measures a single parameter, namely, the flight-time of a neutron scattered between two scintillation counters. Since the direction of the incident neutron is known, the orientation

, of the spectroneter axis with respect to the Incident neutron direction determines the neutron scattering angle $\theta$. Non-relativistically, the incident neutron energy $T$ is given by

$$
\mathrm{T}=\mathrm{T}_{\mathrm{n}} / \cos ^{2} \theta
$$

Here $T_{n}$ is the scattered neutron kinetic energ, wilch is determitned from the neutron flight-time.

We have modifled this spectrometer to measure a second parameter, namely, the energy of the recoll proton in the first detector in a addition to the fight-time of the scattered neutron. The incident neutron energy is then determined from the sum of the recoil proton energy $T_{p}$ and the scattered neutron energy $T_{n}$ as

$$
T=T_{n}+T_{p}
$$

As shown by Eq. (2), the measurement of the 1ncldent neutron energy Is independent of the angle of Incidence on the spectrometer. Since a neutron can scatter from a proton in the finst detector. 
through an angle ranging from 0 to $90^{\circ}$, neutrons inctdent on the spectrometer in the forvard hemisphere can scatter into the second detector. Thus, the spectrometer measures the spectrm of orinfdrectional neutrons integrated over the forward hemisphere. The engle of incidence $\theta$ of a neutron ifith respect to the spectroneter axis can be determined from the kinematic relation

$$
\theta=\tan ^{-1}\left(T / T_{n}\right)
$$

Since the argle of Incidence for each event can be determined from the measured recoll-proton and scattered neutron energles, the events can be complled also to give the differential energy spectra within specifled angular intervals about the spectrometer axis.

In July, 1973, we set up a tro-parameter spectrometer at the Uiversity of Maryland cyclotron and measured the neutron spectrum at $0^{\circ}$ from $71 \mathrm{MeV}$ deuteron bombardient of a thick carbon target. The objectives of this measurement were to confirm the principle of the two-paraneter spectrometer, ard to make a thick-target neutron spectrmm measurement of Interest to the Untversity of pharyland biomedical program. Since the neutron beam is unfdirectional, the technical approach was to analyze the data by both one- and twoparameter techniques. The one-parameter technique, which has been proven, serves as a standand for comarison of the two-parameter measurement. 
For this measurement we used small $2 l_{2}$ in. diam by 2t in. high first detectors and recorded the data on magnetic tape with the Universtty of Beryland's TBM 360/44. on-line computer. The dymamic range of the recoll-proton energifes that could be measured was Indted by the avajlable apparatus to a ratio of about 5 to. 1 . Also, we were lintted by the dimensions of the first detector to spectral measurements in which the angle of incidence of the neutron beam on the spectrometer was small. At large angles of incidence, a sigrificant percentage recoll-protons would escape the $2 l_{\Sigma}$ in. diam first detector. If the recoll-proton escapes, the meastured recoll-proton energy is less than the true enerpy resulting in an erroneous value for the tnctdent neutron energy $T$ and the angle of Inctdence.

2. Expemimental Axpangement

Figure 1 is a didgram of the expertmental arrangement at the University of karyland cyclotron. The 7l-keV deuteron beam was stopped in a 3-inch thick carbon target. Neutrons enttted in the forward direction passed also through a 7/8-1nch thilck berylitum target located about 20-1nches downstream. The beryllium tarot rematned in place from a previous experinient. As shown in FLg. 2, the beryl)fum target was backed with a 7/16-inch thick alumlnum plug and encased in an alundmum cylinder -3-inches in diameter by 2-inches thick. In addition to the beryllium target and aluminum target holder, the neutrons enitted in the forward direction passed also through a 1/8-inch thick aluninum vacuum window located in front of 
71- $\mathrm{HeV}$

Deuteron Beam

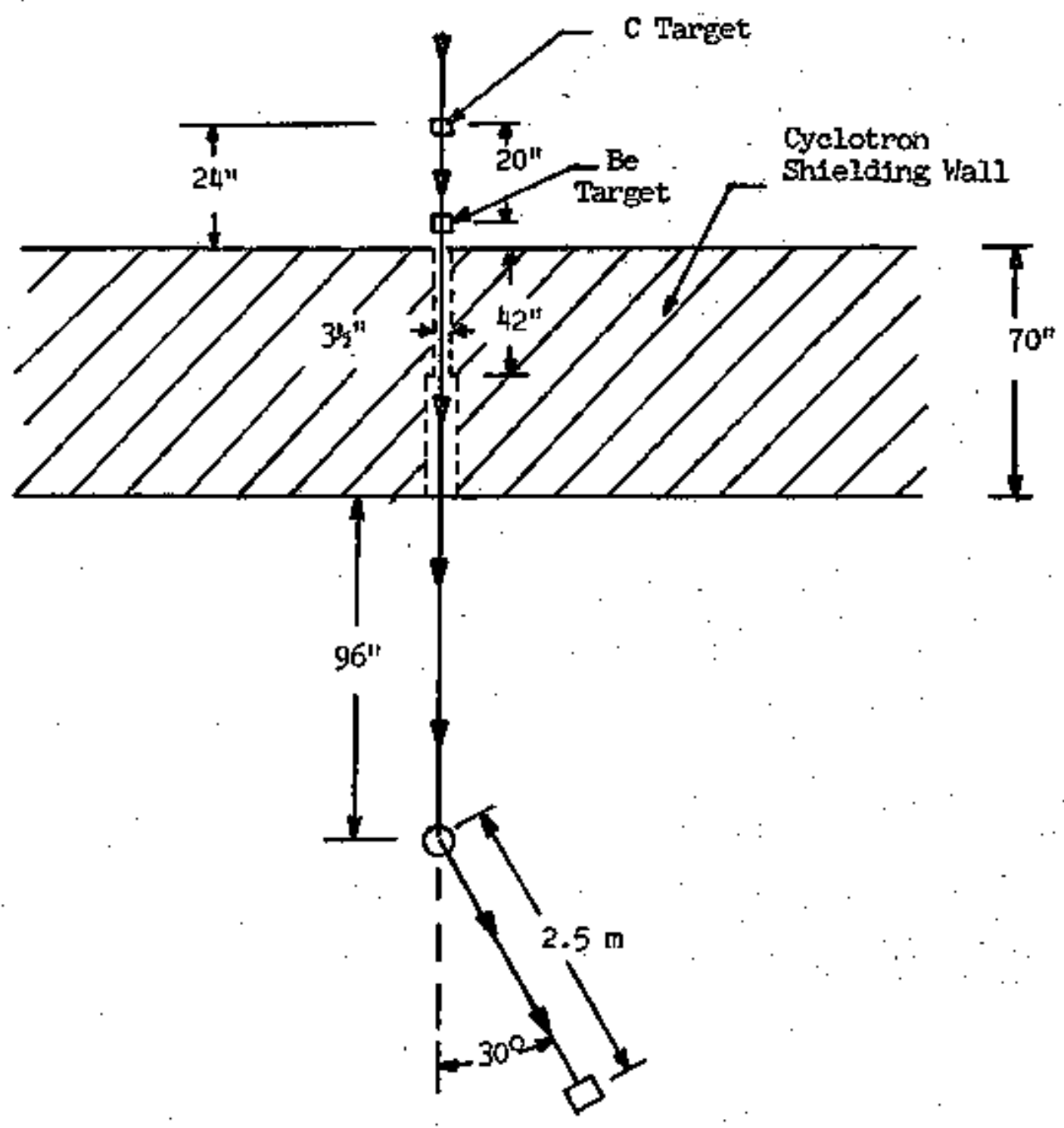

FIG. I Experimental arrangement at the University of Maryland cyclotron. 


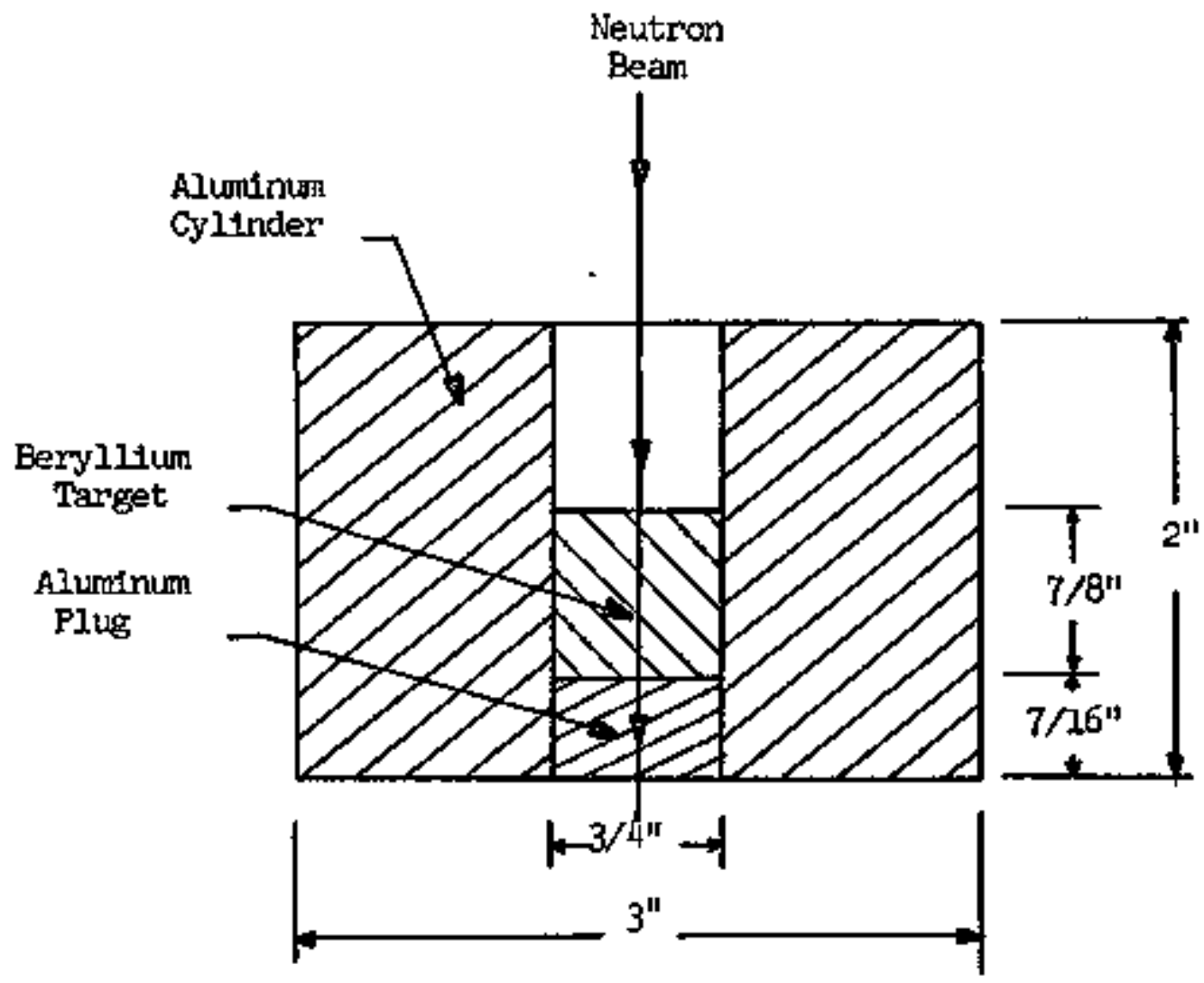

FIG. 2. Diagram of the beryljtum target and Aluninum casing. 
the entrance aperture of collimator. The neutrons enlitted at $0^{\circ}$ were vlewed through a steel collinator $31 / 2$ in. diam by 42 in. lons enbedded in the 70-1nch th1ck cyclotron shlelding wall. The deuteron beam intensity was monitored by integrating the charge deposited in the target.

The neutron spectmm at $0^{\circ}$ was measured with a spectrometer consisting of two scintillation counters shown as D1 and D2 in F1g. 1 . The $\mathrm{DI}$ detector was centered in the neutron beam 6.5 meters from the carbon target. The D2 detector was positioned 2.5 meters from D1 and at an' angle of $30^{\circ}$ with respect to the direction of the Incident neutrons. The $\mathrm{Dl}$ detector consisted of a $2 \frac{1}{2}$ in. diam by $2 l_{2}$ in. high NE-102 or NE-228 scintiliator mounted on an Amperex 56 DVP photomultiplier by means of a $1 \frac{1}{2}$ high tapered lucite light pipe. The D2 detector consisted of a $5 \mathrm{in}$. diam by $4 \mathrm{ln}$. thick NE-102 scintillator mounted on an Amperex 58 AVP photomititiplier. The D1 detector was biased at $3 \mathrm{MeV}$ proton energy; the D2 detector at $5 \mathrm{MeV}$ proton energy . At a threshold of $5 \mathrm{MgV}$ proton energy, the neutron detection efficiency of D2 was typlcally 15 percent for Incident neutrons from 10 to $70 \mathrm{MeV}$.

\section{Measurenents}

In accondance with procedures described by Madey and Waterman (1973), we made separate spectral measurements with NE-228 and NE-102 D1 detectors. Each spectral measurement included simultaneous measurements of the spectrum of neutross plus background, and the spectrum of only the background from accioental or chance coincidences. 
We shall refer to this latter spectrum as the spectrum of accidentals and the former as the spectrum of reals plus accidentals. The spectrum of accidentals was measured with a separate delayed coincldence circuit in the manner descrtbed previously by Madey and Waterman (1973):

Two-parameters were recorded for each colnctence between events in the D1 and D2 detectors. The recorded parameters were the pulse-height in the $\mathrm{Dl}$ detector and the time interval between the Interactions in D1 and D2. These data for each event were recorded on magnetic tape at the output of the $360 / 44$ IBN on-1ine computer at the cyclotron facllity. The scheme for gating the DI detector photomultiplier anode pulse has been described previousiy by Nadey and Waterman (1972).

Measurements contalning more than 50,000 real events were made with each of the above scintillator types for the D1 detector. The count rate of real events was typically 15 counts/ sec with a bean current of 25 nanoamperes.

4. Backgroumos.

The two prinary sources of background in the spectral measurement. are the neutron-carbon interactions in the D1 detector and the chance or accidental coincldences between uncorrelated events in the DI and D2 detectors. Previously, we have determined neutzon-carbon background from separate spectral measurements with NE-102 and lE-228 first detectors in the manner described by Madey and Waterman (1973). In this section, we describe an tmproved technique for subtracting 
carbon background applicable to two-parameter spectral measurements of neutrons incident unidirectionally on the spectrometer. A principel advantage of this improved techrlque is that it requires only one spectral measurement with either the NE-102 or the NE-228 first detector. Also, the former carbon subtraction techrique 1ncreases the uncertainty of the spectral measurenent by about a factor of 2, whereas the new technique does not. Another advantage of the two-parameter carbon subtraction technique is that it rejects also a major fraction of the background from the accidental coincidences that occur in the one-parablet measurement.

In the present experiment, we measured the energy of the recoll proton $\mathrm{T}_{\mathrm{p}}$ and the energy of the scattered neutron $\mathrm{T}_{\mathrm{n}}$. The geometry of the detectors define the neutron scattering arde $\theta_{\mathrm{g}}$ for each event to within $\pm 2.0^{\circ}$. For $n \rightarrow p$ elastic scattering events, the neutron scattering angie is given also by the non-relativistic expression.

$$
\theta_{k}=\tan ^{-1}\left(\mathrm{~T}_{p} / \mathrm{T}_{\mathrm{n}}\right)^{\frac{1}{2}}
$$

He use subscripts on the neutron scattering angle to distinguish that defined by the geonetry from that calculated through the kinematic relation. The techrique for subtracting background from " neutron-carbon interactions consists of calculating the neutron scattering argle from Eq. (4) for each event and rejecting those events for which the caiculated scattering angle does not agree with that defined by the geometry of the detectors. To meet this requarement, a neutron-carbon interaction in DI that produces a neutron with energy 
$T_{n}$ detectable in D2 mist be accompanted by a light output in $\mathrm{Dl}$ equivalent to a recoil proton with energy $T_{p}=T_{n} \tan ^{2} \theta_{g}$. In other words, to be accepted as an n-p elastic scattering event, the measured proton and scattered neutron energles must have the energy ratio $T_{p} / T_{n}=\tan ^{2} \theta^{*}$. Since carbon Inelastic reactions that produce a neutron and a charged particle are many-bodied, there is no kinematic requirement for the "proton" and neutron energdes to occur In the above ratio requated for n-p elastic scattering; hence, it is expected that this restriction will refect most neutron-carbon background events. Later we will present experimental evidence supporting this expectation.

Also, the rejection of events that do not give a neutron scattering angle corresponding to that for $n-p$ elast1c scattering reduces the backgroumd of accidental coincidences. This reduction In the background of accidental colncidences is expected because the accidental colncidences arise from uncorrelated events in the first and second detectors which have a wide range of recoil proton and scattered neutron kinetic energies.

Figure $3(a)$ is a compilation of the nettron scattering angles obtained from Eq. (4) for each event in the neutron spectrum measured with the $\mathrm{ME}-228 \mathrm{Dl}$ detector. Simfiariy, Fig. 3(b) is a corpilation of the neutron scattersing angles obtatned for each event in the background spectrum of accidental coincidences. The distribution of meutron scattering angles for the real events is obtained by subtracting the background distribution show in Fig. 3(b) from that show in 


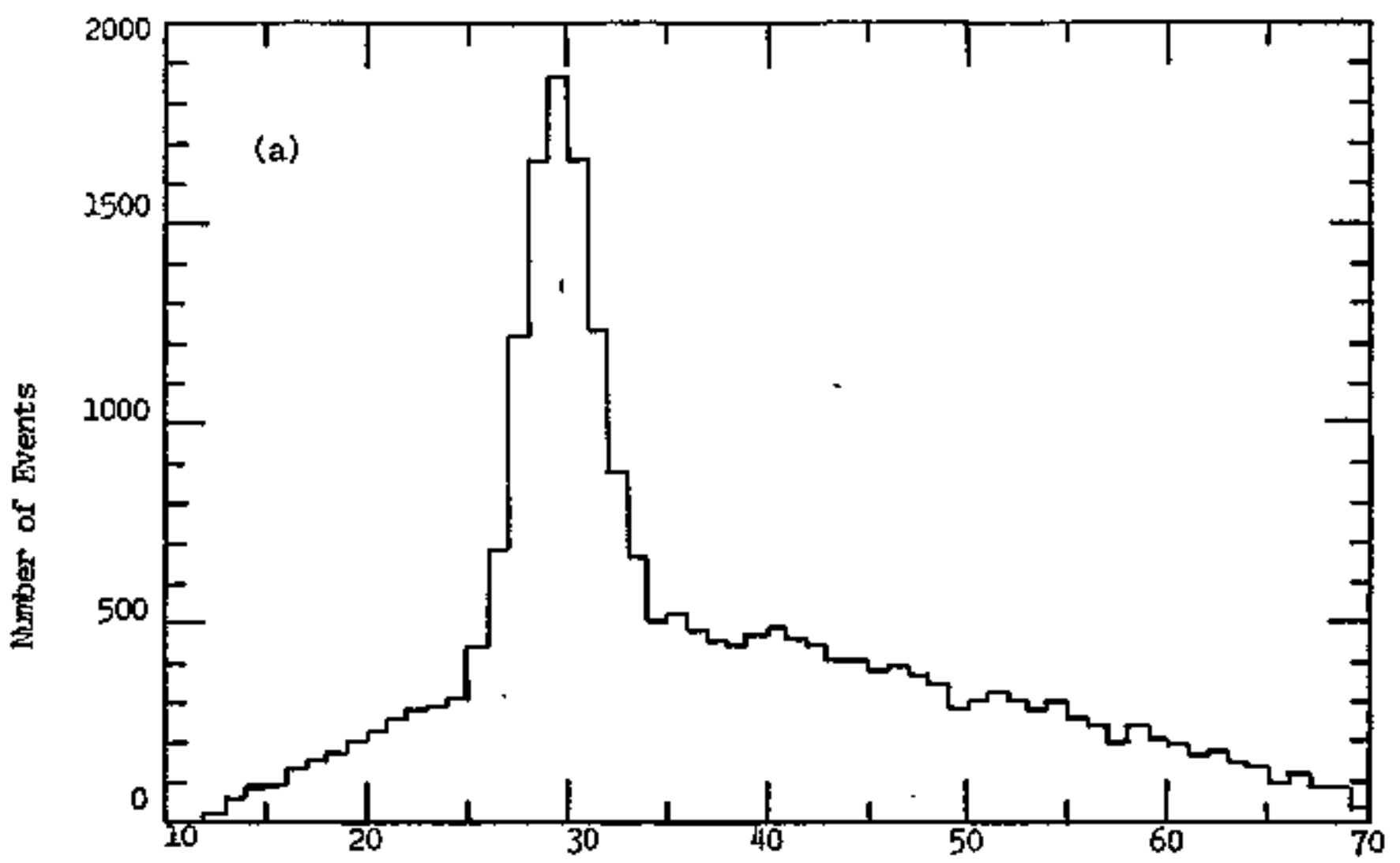

Heution Scattering Angle, $\theta$, (deg)

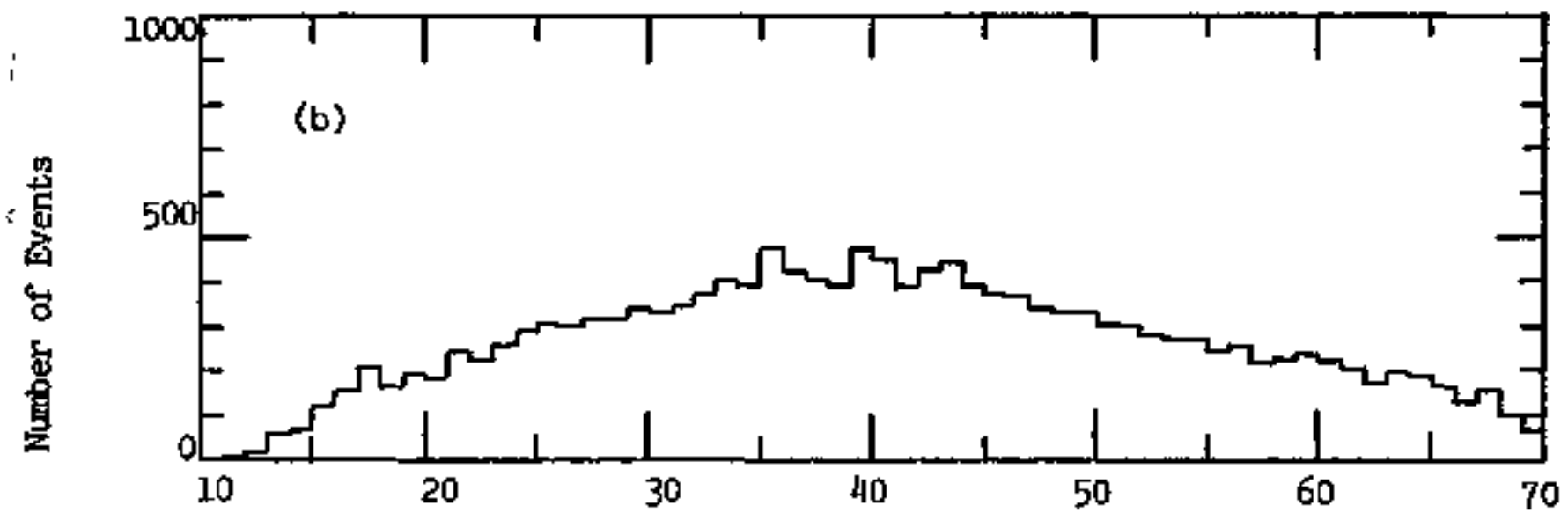

Neutron Scattering Aingle, $\theta$ (deg)

FIG. 3 The distribution of neutron scattering angles given by

(a) the spectrum of real plus accidental coincldences and

(b) the spectrum of accidental coincldences measured with the NE-228 first detector. 
- Fis. 3(a). Figures $4(a)$ and $4(b)$ are the distributions of neutron scattering angles obtained for the real events only in the spectral measurements made separately with the NE-228 and NE-102 DI detectors. In both Figs. $4(a)$ and $4(b)$, the distribution of neutron scattering angles consists of a well defined peak centered at $29.5^{\circ}$ with "tails" extending down to about $10^{\circ}$ and up to about $50^{\circ}$.

The fact that both distributions are centered at $29.5^{\circ}$ indicates that the second detector was positioned at an angle of $29.5^{\circ}$ with respect to the neutron beam rather than at $30^{\circ}$. The full-width at half-maximu (nim) of the distribution shown $1 \mathrm{n} F \mathrm{f} / \mathrm{a}$ (a) about $4^{\circ}$; that in Flg. $4(\mathrm{~b})$ is about $3^{\circ}$. The difference in the widtis of the distributions reflects the poorer pulse-helght resolution of the NE-228 detector in comparison with the NE-102 detector. (We discuss the energy resolution of these two detectors in the next section.) Por a Gaussian distribution, the fwrm is equal to 2.35 standard deviations. Assuming the distributions of neutron scattering angles are Gaussian, we find that the standard deviation of the distribution shown in Fig. $4(\mathrm{a})$ is $1.7^{\circ}$ and that shown in Fig. 4(b) is $1.3^{\circ}$.

Now we describe how we establushed the angular interval of neutron scattering angles corresponding to n-p elastic scattering. We used the criterion that the angular interval include at least 99\% of the n-p elastic scattering events. Assuming that the distribution of neutron scattering angles is Caussian, find that $.99 \%$ of the events w1ll occur within 2.58 standard deviations, which 


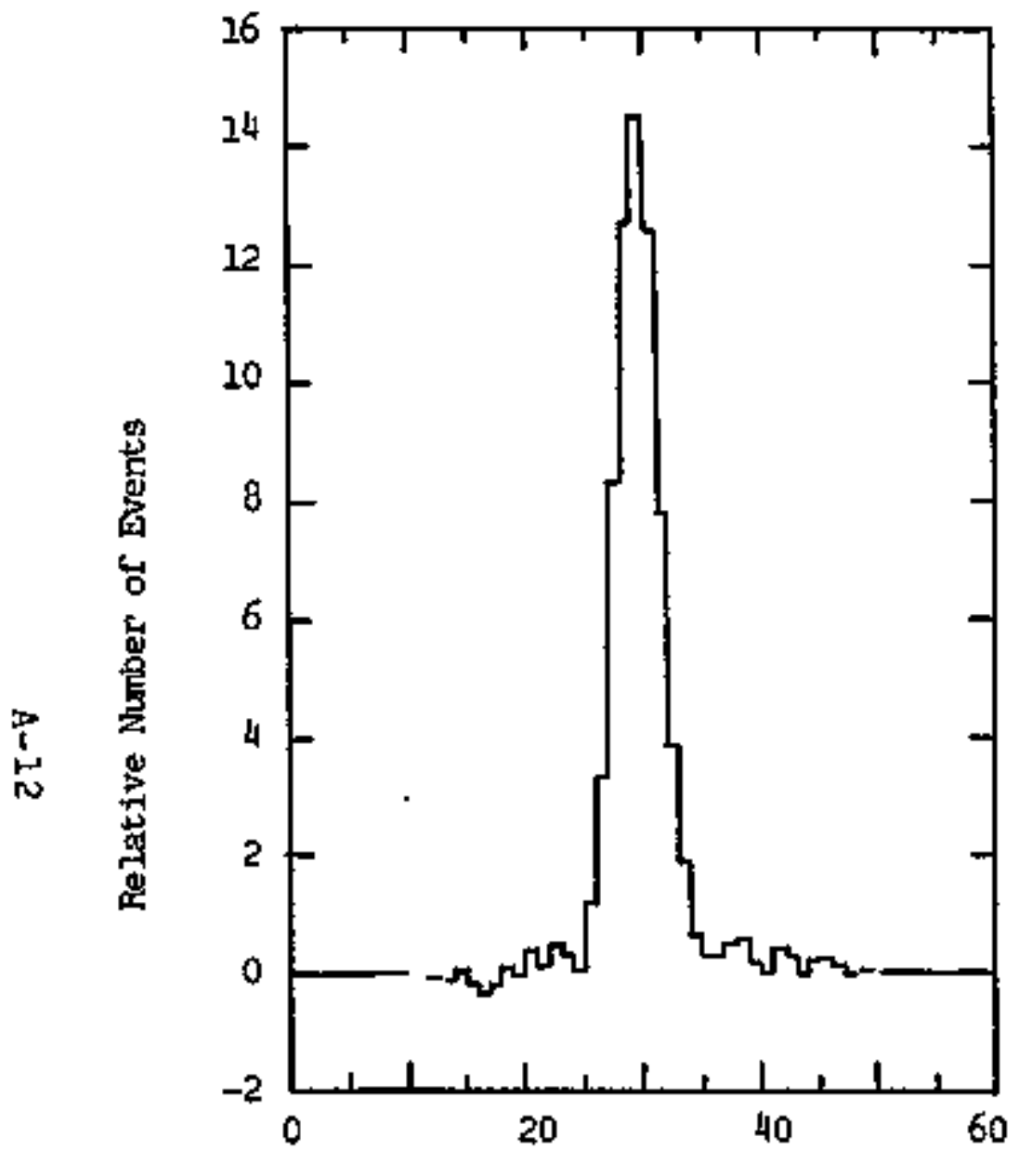

Neuteron Scattering Angle, $\theta$ (deg)

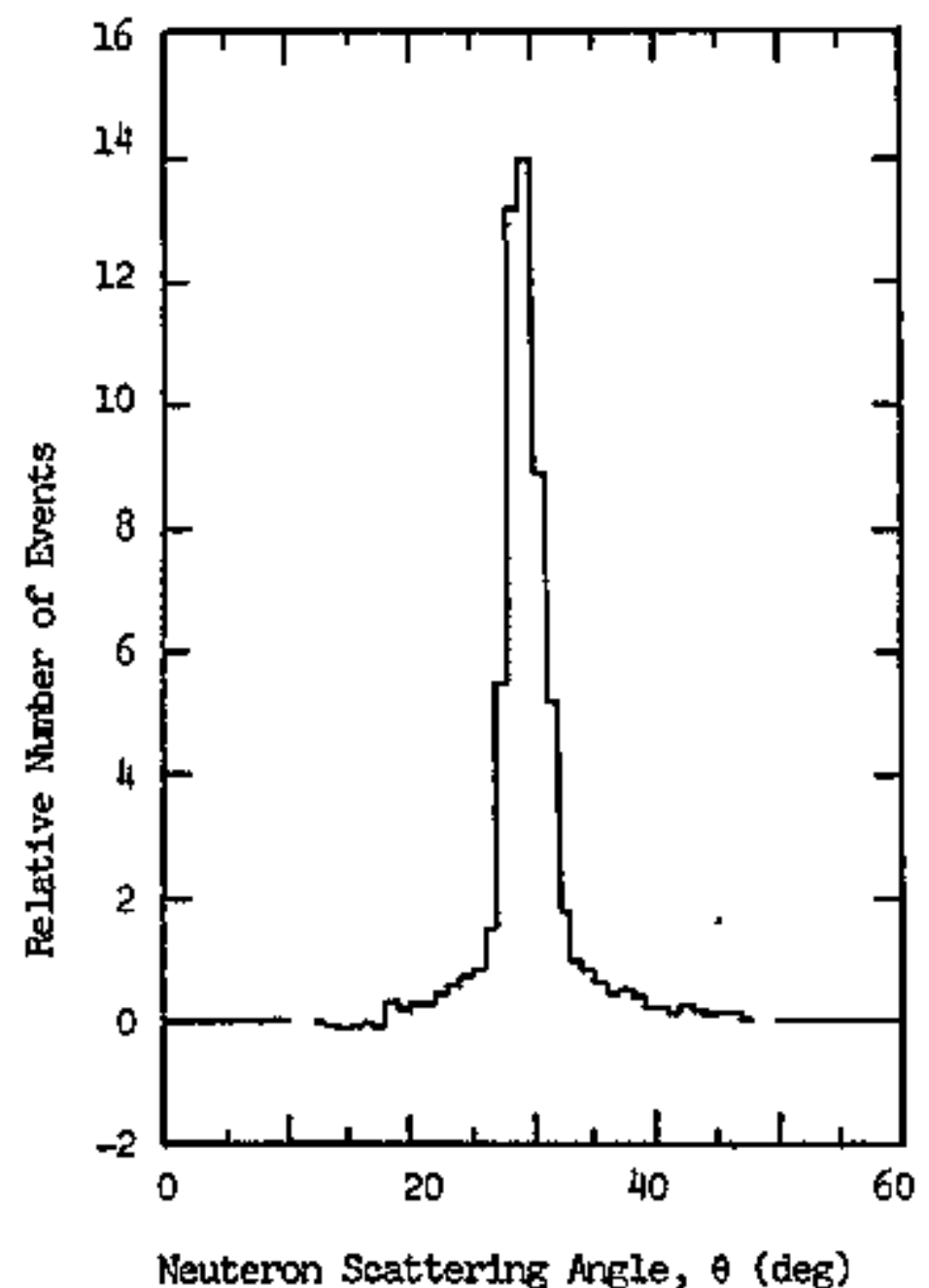

Neuteron Scattering Angle, $\theta$ (deg)

- FIC. 4 The distribution of neutron scattering angles for real events only in spectral measurements with (a) the AL-228 and (b) the NE-102 detectors. 
, corresponds to the full-width at 0.036 of maximum. Since the data is complled in a histogram with bin widths of $1^{\circ}$, it is convenient for processing the data to select angular intervals that include an integralnumber of bins. The Intervals selected are from 25 to $34^{\circ}$ for the distribution of scattering angles shown in Fig. 4(a) and from 26 to $33^{\circ}$ for the distribution shown in Fig. 4(b). Each of these Intervals corresponds to about 2.7 standard deviations and includesmore than $99 \%$ of the $n-p$ elastic scattering events.

By Inspection of Flg. 4, we see that the talls of the distribution deviate from a Gaussian distribution. About $6 \%$ of the events In Fig. $4(a)$ are outside the interval from 25 to $34^{\circ}$. Sinflarly, about $15 \%$ of the events in $\mathrm{Fig}$. 4(b) are outside the interval from 26 to $33^{\circ}$. The events outside the intervals defined for $n-p$ elastic scattering are attributed to background from neutron-carbon interactions in the $\mathrm{Dl}$ detector. Since $\mathrm{NE}-228$ has a higher hydrogen-to-carbon ratio than $\mathrm{NE}-102$, less carbon background is expected in the spectral measurement made with the NE-228 Dl detector.

In the following paragraph, we present experimental evidence that the events which give neutron scattering angles outside the interval defined above for n-p elastic scattering can be attributed to carbon background. We deliberately made separate spectral measurements with $\mathrm{NE}-102$ and $\mathrm{NE}-228$ first detectors in order to calculate the carbon background from these measurements in the manner described previously by Madey and Waterman (1973). Then we compared the percentage of carbon background events calculated in this 
manner from the $\mathrm{NE}-102$ and $\mathrm{NE}-228$ spectral measurements with the percentage of backgrounds events in each spectral measurement that give neutron scattering angles outside the interval defined for $n-p$ elastic scattering. In Table $I$, we list the percentage of carbon background obtained from the NE-102 and NE-228 subtraction tecknique at detector thresholds of 3,5 , and $7 \mathrm{MeV}$ proton energy. The uncertainties listed in Table I reflect the uncertainty in normalizing the NE-102 and NE-228 spectral measurements.

In Table II, we list for the same detector thresholds the percentage of the total number of events in the $\mathrm{NE}-102$ and NE-228 spectral measumements that give neutron scattering angles outside the intervals defined for n-p elastic scattering. In Table II, the uncertainties represent the statistical uncertainty in the number of events. Except for the $\mathrm{NE}-228$ spectral measurement at a detector threshold of 3 HeV proton energy, the values in Tables I and II agree within one standard deviation. This agreement indicates that those events which give neutron scattering angles outside the intervals corresponding to n-p elast1c scattering can be attributed to neutron-carbon interactions. The fact that the difference between corresponding numbers in Tables I and II is small or zero Indicates that the percentage of carbon background events that give neutron scatterirg angles within the interval defined for $n-p$ elastic scattering is small. 


\section{TABLE I}

The percentage of carbon background at detector thresholds of 3,5 , and $7 \mathrm{MeV}$ proton energy determined from seperate spectral measurements w1th $\mathrm{NE}-228$ and $\mathrm{NE}-102 \mathrm{f}$ irst detectors in the manner described by Madey and Waterman (1973).

Threshold in

Proton Energy (MeV)
Garbon Background (E)

NE-228 Detector NE-102 Detectior

$\begin{array}{rlrl}10.1 & \pm 1.9 & 17.9 & \pm 3.1 \\ 5.8 & \pm 1.8 & 10.7 & \pm 3.2 \\ 1.1 & \pm 1.7 & 2.3 \pm 3.3\end{array}$


TABLE II

The percentage of events that give neutron scattering angles outside the 1ntervals* defined for n-p elastic scattering.

Threshold in

Proton Energy (MeV)

3

5

7

\begin{tabular}{cr}
$\frac{\text { Percentage of Events ( } \%)}{\text { NE-228 Detector }}$ & NE-102 Detector \\
\hline $6.1 \pm 1.1$ & $15.1 \pm 0.7$ \\
$3.1 \pm 1.2$ & $9.4 \pm 0.7$ \\
$1.4 \pm 1.0$ & $3.2 \pm 0.8$
\end{tabular}

* Angular 1ntervals defined for n-p elastic scattering are: $25^{\circ} \leq \theta \leq 34^{\circ}$ for NE-228 and $26^{\circ} \leq \theta \leq 33^{\circ}$ for NE-102, 
- From Figs. $3(a)$ and $3(b)$, it can be seen that the rejection of all events that do not give neutron scattering angles within the Interval defined for n-p elastic scattering will reject also a mafor fraction of the background from accidental colncidences that occur In the one-parameter measurements. In the present expertment, about $75 \%$ of the accidental coincidences are refected in this manner. The backgroumd of accidental cofncidences remaintrg in the $n-p$ elastic scattering region is removed by subtracting the energy spectrum given by the accidental colncidences fror that of the real events plus accidentals. This adititional criterion for subtracting accidental coincidences permits the two-parameter spectroneter to measure unidirectional neutrons in a higher background enviromment then possible previously with the oneparameter spectrometer.

5. Energy Resolution

In this section, we compare the energy resolution of the oneand two-parameter spectral measurements. In the one-parameter aralysis of the data, the incident neutron energy is determined from Eq. (1) :

$$
T=T_{n} / \cos ^{2} \theta
$$

Here $T_{n}$ is the scattered neutron energy and $\theta$ is the neutron scattering angle. Applying the law of propagation of mall errors to Eq. (1), we find that the relative uncertalnty in the measurement of the incident neutron energy can be written as 


$$
\Delta T / T=\left[\left(\Delta T_{n} / T_{n}\right)^{2}+(2 \tan \theta c \theta)^{2}\right]^{\frac{1}{2}}
$$

Here $c \theta$ is the uncertainty in the neutron scattering angle as a result of the fInite dimensions of the $\mathrm{Dl}$ and $\mathrm{D} 2$ detectors, and $\Delta T_{n} T_{n}$ is the relative uncertainty in the measurement of scattered neutron energy defined as

$$
\Delta T_{n} / T_{n}=2\left[(\Delta x / x)^{2}+(\Delta t / t)^{2}\right]^{t / 4}
$$

Here $\Delta x / x$ is the relative uncertainty in the flight-path as a result of the finite dimensions of the detectors, and $t \mathrm{t} / \mathrm{t}$ is the relative uncertatnty in the flight-time as a result of the intrinsic time dispersion of the system.

In the two-parameter analysis, the Incident neutron energy 1s determined from Eq. (2):

$$
T=T_{n}+T_{p}
$$

Here $\mathrm{T}_{\mathrm{n}}$ and $\mathrm{T}_{\mathrm{p}}$ are the measured scattered neutron and recoll proton kinetic energies, respectively. The relative uncertainty in the measurement of the incident neutron energy by the two-parameter technique can be expressed as

$$
\Delta T / T=\left[\left(\frac{\Delta T_{n}}{T_{n}} \cdot \frac{T n_{n}}{T}\right)^{2}+\left(\frac{\Delta T_{p}}{T p} \cdot \frac{T}{T}\right)^{2}\right]^{\frac{3}{2}}
$$

Since $T_{n}=T \cos ^{2} \theta$ and $T_{p}=T \sin ^{2} \dot{\theta}, E q$. (7) can be rewritten as 


$$
-\quad \Delta T / T=\left[\left(\frac{\Delta T_{n}}{T_{n}} \cos ^{2} \theta\right)^{2}+\left(\frac{\Delta T_{p}}{T_{p}} \sin ^{2} \theta\right)^{2}\right]^{\frac{5}{2}}
$$

To calculate the energy resolution of the two-paraneter spectrometer, we need a general expression for the relative uncertainty $\Delta \mathrm{T}_{\mathrm{p}} / \mathrm{T}_{\mathrm{p}}$ in the measurement of the recolil proton energy. Such an expression can be derived from the pulse-height resolution observed in the Compton spectra of monoenergetic garma-rays in the manner described in the following paragraph.

Figure 5 is a plot of the Na-22 Compton spectrum of observed with the $2 \frac{1}{2}$ in. diam by $2 \frac{1}{2}$ in. $h$ NE-228 liquid scintuluator. The Compton peak is taken to correspond to the maximun Compton electron energy produced by the assoc1ated gamma-ray. For Na-22, the Compton peak corresponds to the $1.06 \mathrm{MeV}$ electron energy. As shown in Fig. 5, the Compton pealk 1s located at channel $33.5 \pm 1.5$; the halfmaximm at channe1 42.5. In Fig. 6 , we have plotted the channel numbers corresponding to peaks of Mi-54, Na-22, and Th-220 ganme-ray smurces versus the corresponding electron energies of $0.64,1.06$, and $2.39 \mathrm{MeV}$ respectively. The solid line drawn through the Conpton peak positions gives the electron energy $\mathrm{T}_{\mathrm{e}}$ corresponding to each channel of the pulse-height spectra. From this plot, we can determine the electron enersy corresponding to the channel number of the half-maxirum of a Compton peak and the corresponding pulse-height resolution $\Delta \mathrm{T}_{\mathrm{e}} / \mathrm{T}_{\mathrm{e}}$ in electron energy, where $\Delta \mathrm{T}_{\mathrm{e}}$ is the haif-width at half-maximum of the Corpton peak in electron energy. Table III lists the pulse-height resolutions in electron engy determined from 


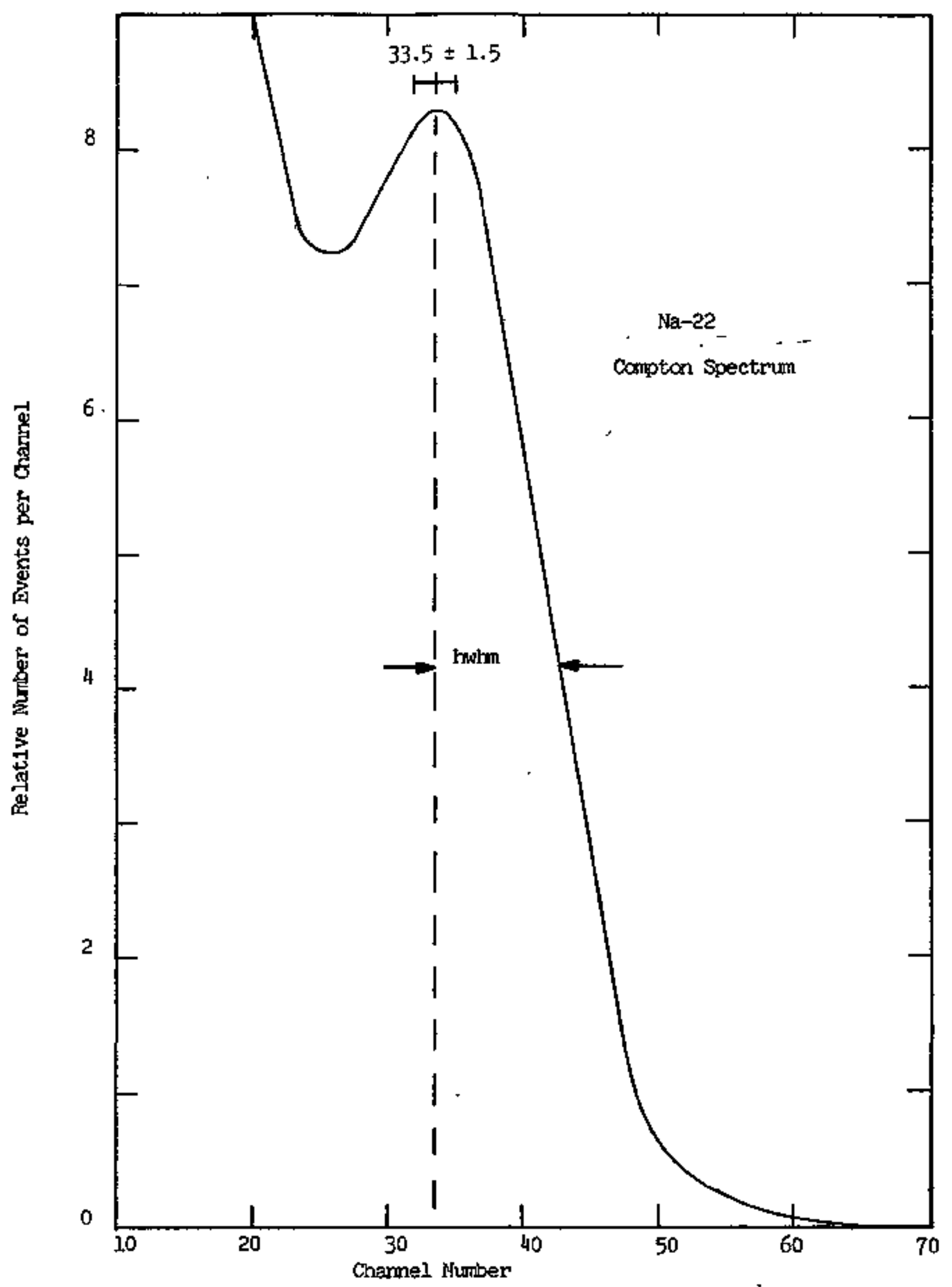

FIG. 5. Sodium-22 Compton spectrum observed with a $2^{\text {s }}$ in. diam by $2 k_{1}$ in. ht. NE-228 liquid scintillator. 


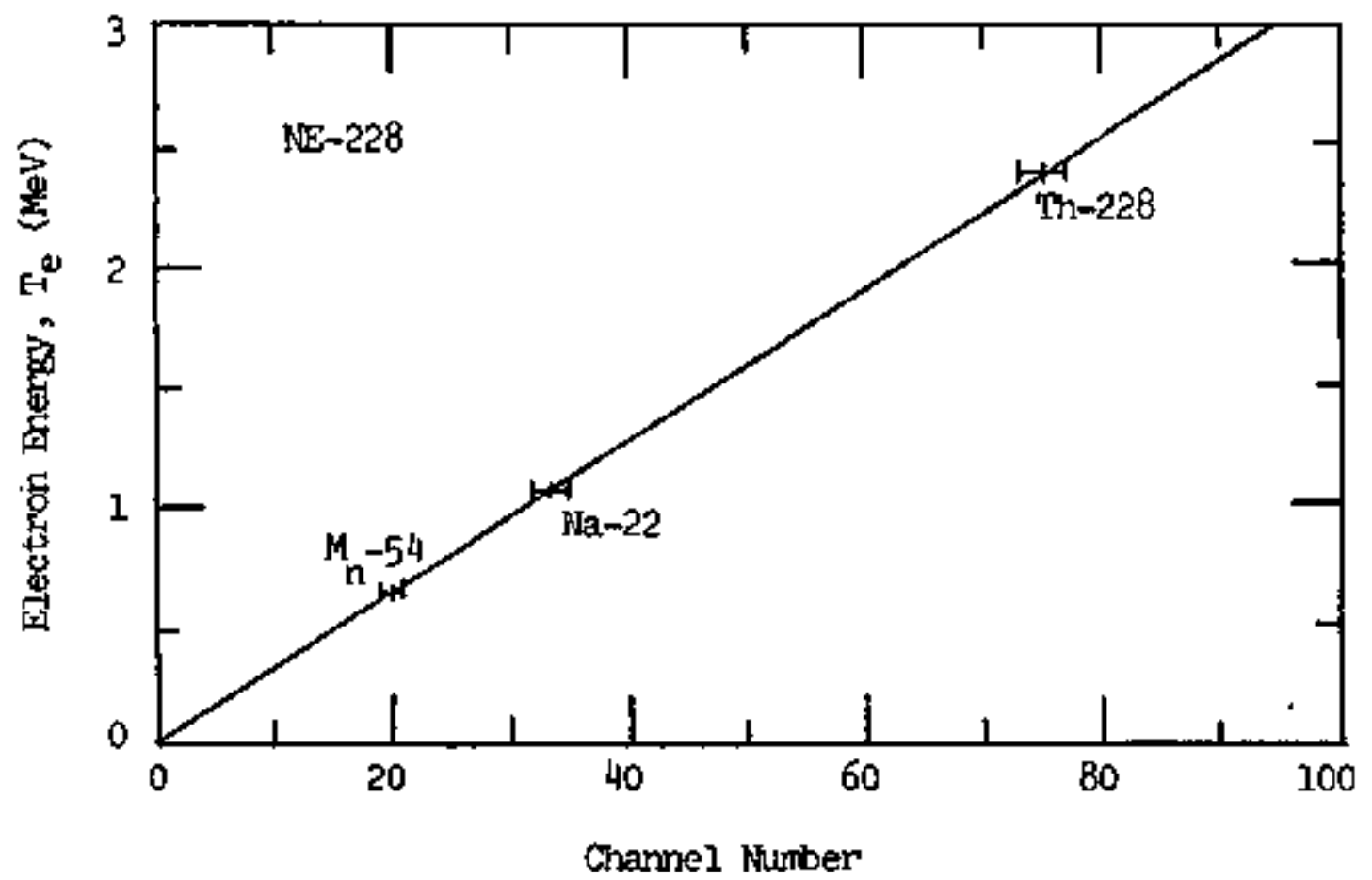

FIG. 6 Plot of the positions of the Conpton peacs observed whth $\mathrm{kn}-54$, Nez-22, and Th-228 gama-ray sources verses the corresponding electron energy of the Compton peak. 
TABLE III

Pulse - helght resolution in electron energy determined from $\mathrm{Mn}-54, \mathrm{Na}-22$, and $\mathrm{Th}-228$ gamma-ray sources for the 23. in. dlam. by $2 \frac{1}{2}$ in, ht, NE-228 and NE-102 scintiliators used in the JuIy 1973 neutron spectral measurement at the University of Naryland.

\begin{tabular}{|c|c|c|c|}
\hline Gamma & Electron Energy & \multicolumn{2}{|c|}{ Resolution, $\Delta \mathrm{T} / \mathrm{T}(\mathrm{z})$} \\
\hline Source & $\mathrm{T}_{\mathrm{e}}(\mathrm{MeV})$ & $\mathrm{NE}-228$ & $\mathrm{NE}-102$ \\
\hline $\mathrm{Mn}-54$ & 0.64 & 30.0 & 14.7 \\
\hline $\mathrm{Na}-22$ & 1.06 & 26.8 & 12.6 \\
\hline$T h-228$ & 2.39 & 24.0 & 10.7 \\
\hline
\end{tabular}


Mn-54, Na-22, and Th-228 ganma-ray sources for the $2 \mathrm{l}_{2}$ In. diam by 2t: in. $h, N E-102$ and $N E-228$ scintillation counters used in the present experiment.

Garlfck and wright (1952) have shown that the distribution of pulse-heights at the output of the photomultiplier may be repregented by a Gaussian function with a wiath that varies approxfmately as the square-root of the mean output pulse height. In Fig. 7, we have plotted the pulse-height resolution $L \mathrm{~T} / \mathrm{T}_{\mathrm{e}}$ in electron energy versus $\mathrm{T}_{\mathrm{e}}^{-\frac{1}{2}}$. As Fig. 7 indicates, the pulse height resolution in electron energy can be represented by a stratght line of the form

$$
A T_{e} / T_{e}=a_{e} T^{-\frac{1}{s}}+b
$$

For the NE-228 and NE-102 scint11lators used in the present experinent, the constants $\mathrm{a}$ and $\mathrm{b}$ in $\mathrm{Eq}$. (9) above have the following values:

$\begin{array}{ccc}\text { Sclintillator } & \text { a } & \underline{b} \\ \text { NE-228 } & 0.096 & 0.177 \\ \text { NE-102 } & 0.068 & 0.061\end{array}$

By substituting the above values of the constants a and b into Eq. (9), we can determine the pulse-helght resolution $\Delta \mathrm{T} e^{/ T}$ for any given electron energy $\mathrm{T}_{\mathrm{e}}$.

Figure 8 relates the electron energy to the proton energy for the same light output in an NE-102 and an NE-228 scintillator. The solld curve delineates the response of $102-102$ seint1llator calculated by Gooding and Pugh (1960, 1961) and verifled experimentally by Madey and Waterman (1972). The dashed curve delineates the resporise of $\mathrm{NE}-228$ 


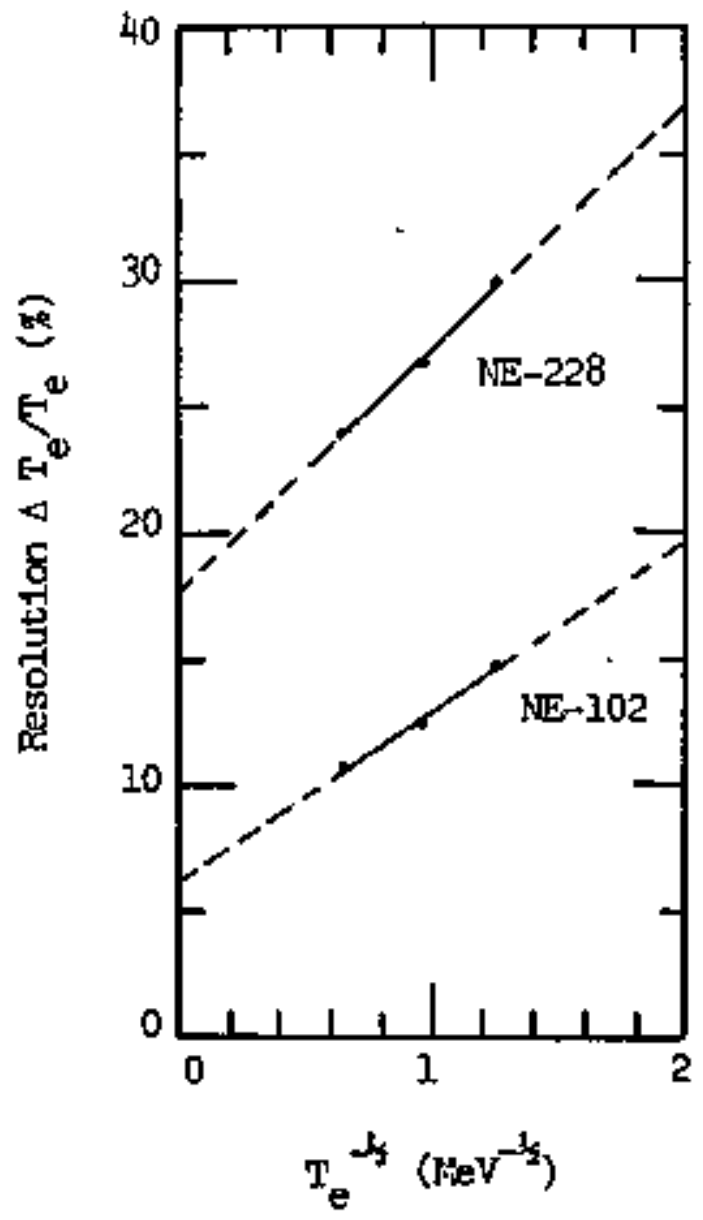

FIG. 7 Fulse height resoiution in electron energy of the $2 \frac{1}{2}$ in. diam. by 24 In. high $\mathrm{KE}-102$ and $\mathrm{NE}-228$ first detectors used in the July 1973 spectral measurement at the Untversity of Maryland cyclotron. 


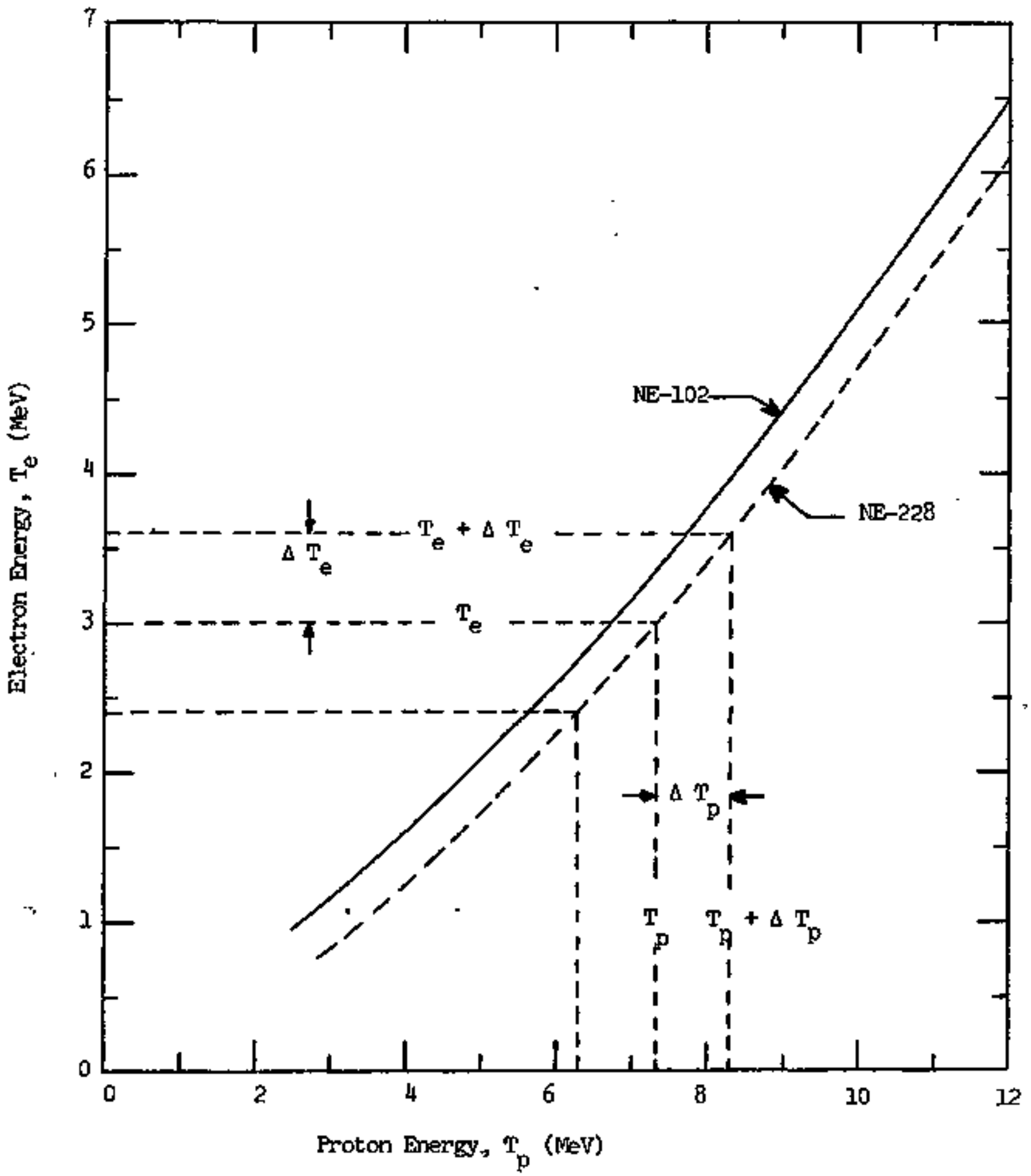

FIG. 8 Felationship between the electron energy and the proton energy for the same ljght output in an INE-102 and an NE-228 scintillator. 
scintiliator measured by Madey and Waterman. In Flg. 8, we 11 lustrate the relationship of the pulse-height resolution in proton enery $\Delta \mathrm{T}_{\mathrm{p}} / \mathrm{T}_{\mathrm{p}}$ to that in equivalent electron energy $\Delta \mathrm{T}_{\mathrm{e}} / \mathrm{T}_{\mathrm{e}}$. It is evident from Fig. 8 that for the same light output, the pulse-height resolution $\Delta \mathrm{T}_{\mathrm{p}} / \mathrm{T}_{\mathrm{p}}$ in proton - energy is better than that $\Delta \mathrm{T} / \mathrm{T}_{\mathrm{e}}$ In equivalent electron energy.

In Table $\Gamma$, we list the pulse-hetght resolution in proton energy of the $2 \frac{1}{2}$ in. dian by $2 l_{2}$ in. $h$. NE-228 and NE-102 scint1liators used in the July 1973 neutron spectral measurement at the Untversity of Maryland for 3, 5, 10, and $15 \mathrm{MVV}$ recoli-protons. The values listed in Table IV were obtained by first determining the electron energy $\mathrm{T}_{\mathrm{e}}$ corresponding to $\mathrm{T}_{\mathrm{p}}$ from $\mathrm{F}$ is. 8 and then determoning the pulse-helght resolution $\Delta \mathrm{T}_{\mathrm{e}} / \mathrm{T}_{\mathrm{e}}$ in electron energy from Eq. (9). The corresponding pulse-height resolution $\Delta \mathrm{p}_{\mathrm{p}} / \mathrm{p}$ was then determined graphlcally frow $\Delta \mathrm{T} / \mathrm{e}_{\mathrm{e}}$ using $\mathrm{F} 4 \mathrm{~s} .8$.

Figure 9 is a plot of the values listed in Table IV for the pulse-height resolution $\Delta T_{p} / T_{p}$ in proton energy versus $T_{p}^{-k_{2}}$. As Fig. 9 indicates, the pulse height resolution in proton energy can be represented by a strafght ine of the form

$$
\Delta \mathrm{T}_{\mathrm{p}} / \mathrm{T}_{\mathrm{p}}=\mathrm{c} \mathrm{T}_{\mathrm{p}}^{-\mathrm{d}_{\mathrm{i}}}+\mathrm{d}
$$

where the constants and $c$ and $d$ have the following values. 


\section{TABLE IV}

Pulse-height resolution in proton energy of the $2 l_{2}$ in dian by 2/2 in. ht. NE-228 and NE-102 scintillators used in the July 1973 neutron spectral measument at the University of Maryland for $3,5,10$, and $15 \mathrm{MeV}$ recoil-protorls.

Proton Energy,

$\mathrm{T}_{\mathrm{p}}$ (MeV)

3

5

10

15 $\frac{\text { Resolut1cn, } \Delta \mathrm{T}_{\mathrm{p}} / \mathrm{T}_{\mathrm{p}}(\mathrm{s})}{\underline{\mathrm{NE}-228} \underline{\mathrm{NE}-102}}$

18.3

26.0

21.6

9.0

15.0

7.0

14.5

6.0 


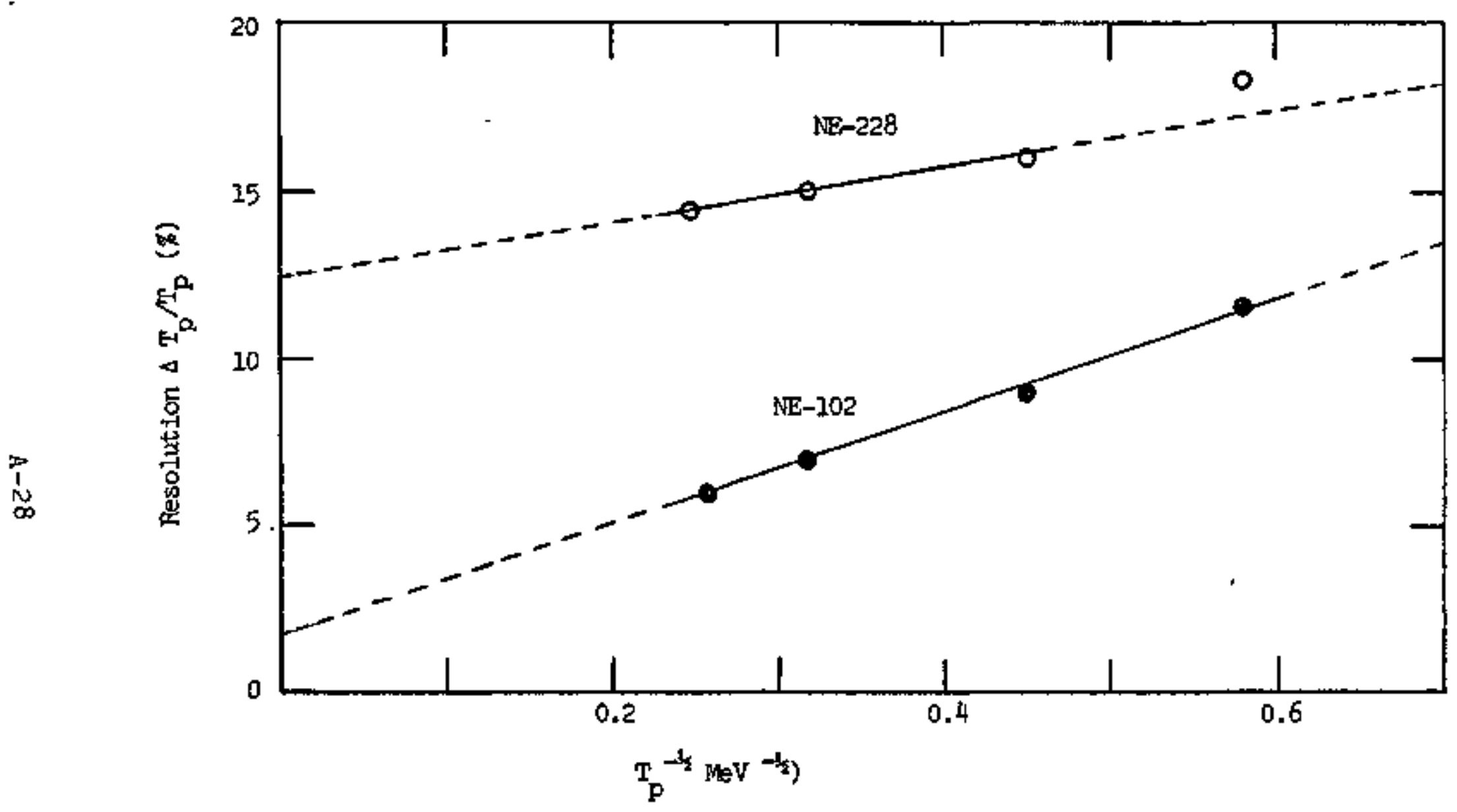

FIG. 9 Pulse-height resolution in proton energy of the $2 \frac{1}{4}$ in diam by $2 \frac{4}{2}$ in high NE-102 and NE-228 fyrst detectors used in the July, 1973, spectral measurement at the Untiversity of thryland cyclotron. 


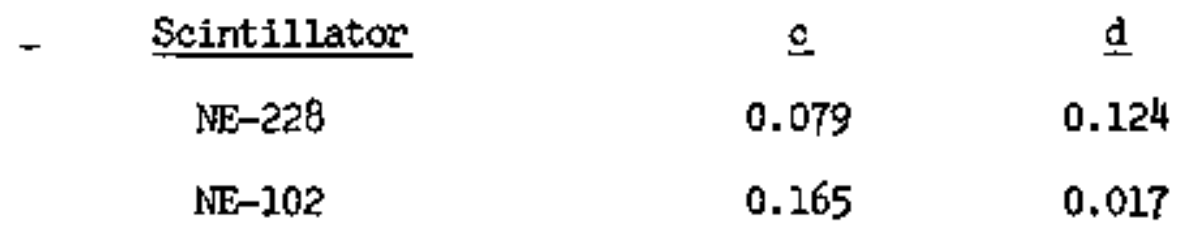

By substituting the appropriate values for the constants $c$ and $d$ In Eq. (10), we have a general expression for the uncertatinty $\Delta T_{p} / T_{p}$ in the measurement recoll-proton energy. This expression can be used in Eq. (10) to calculate the energy resolution of the two-parameter spectrometer.

In Table V, we list the values of the energy resolution calculated from Eq. (5) for the one-parameter spectrometer and rram Eq. (10) for the two-paraneter spectrometer. Values of the twoparameter spectrometer are given for both $\mathrm{NE}-102$ and $\mathrm{NE}-228 \mathrm{DI}$ detectors. The values of the energy resolution listed in Table $\mathrm{V}$ Indicate that the resolution of two-parameter measurenent with the $\mathrm{NE}-228 \mathrm{DI}$ detector is simflar to that of the one-parameter measurement and that of the two-parameter measurement with NE-102 Dl detector is somewhat better than the one-parameter measurement. 6. Analysis

Analysis of the data proceeded through flve basic steps: (1) Calculation of the neutron scattering angle for each event and the rejection of those events that do not correspond to n-p elastle scattering. (2) Determination of the incldent neutron energy for each event by one- and two-paranteter techriques. (3) Compilation of histcgrams of the one- and two-parameter energy spectra. The spectra of the reals plus accidentals and that given by the

$$
A-29
$$


TABLE V

Energy resolution of the che- and two-parameter spectral measurements with $2 \frac{1}{2}$ in. diam by $2 / 2$. high NE-102 and $N E-228 \mathrm{Dl}$ detectors for neutron energles from 10 to $70 \mathrm{MeV}$.

Incident Neutron

Energ, T (MeV)

10

20

30

40

50

60

70
Spectrometer Energy Resolution, $\Delta T / T$ ( $)$

One-Parameter Two-Parameter (NE-102) Two Parameter (NE-228)

4.7

4.6

5.5

5.2

4.5

5.5

5.6

4.6

5.6

6.0

4.8

5.8

6.5

5.1

6.0

6.8

5.3

6.2

7.1

5.5

6.4

The above values of the energy resolution were calculated from Eqs. (5) and (10) for the following parameters: $x * 250 \mathrm{~cm}, \Delta x=5.1 \mathrm{~cm}, \theta=29.5^{\circ}, \Delta \theta=1.0^{\circ}, \Delta t=0.8$ nsec. 
accidental coincldences were conpiled in separate histogrems.

Subtraction of the energy spectrum given by the accidental coincidences from that of the reals plus accidentals. (5) Determination of the energy spectrum in absolute units. Steps (1) through (4) have been described earlier or do not require further elaboration. In the following paragraph, we describe step (5), the determination of the spectrum in absolute units of the neutron yield $Y(T, \Omega)$ in units of neutrons/deuteron-HeV-sr.

The neutron y1eld $Y(T, \Omega)$ in untts of neutrons/deuteron-NeV-sr for each energy interval $6 \mathrm{~T}$ of the spectrum is given by the expression

$$
Y(T, \Omega)=\frac{x_{T}{ }^{2} R(T)}{N_{d} n_{H} \Omega V \varepsilon_{2}(T)(\delta / d \Omega)(T, \theta) G(T) \delta T}
$$

where $x_{T}$ is the distance between the centers of the target and the $D 1$ scintillator, $R(T)$ is the number of events observed in the energy Interval $\delta T$ centered at the incident neutron energy $T, N_{d}$ is the total number of deuterons incident on the target cuming the measurement, $\mathrm{n}_{\mathrm{H}}$ is the numberical density of hydrogen in the $\mathrm{Dl}$ scintillaotr, $\mathrm{a}$ is the solid angle subtended by the D2 scintillator at the center of the DI scintillator, $V$ is the volume of the Dl scintillator, (do/dn) $(T, \theta)$ is the laboratory differential n-p scattering cross section for scattering a neutron w1th energy $T$ through an angle $\theta, G(T)$ is the total neutron attenuation factor $F(x$. incldent and scattered neutrons in $\mathrm{DI}, \varepsilon_{2}\left(\mathrm{~T}^{\prime}\right)$ is the neutron detection efficiency of the $\mathrm{D} 2$ detector for scattered neutrons with energy T" and $\delta T$ is the energy width of the interval. 
- The energy spectrum in absolute units is determined by calculating the neutron yield $Y$ for each interval of the energy spectrum from Eq. (11). The energy Independent terms in Eq. (11) have the following values: $x_{\mathrm{T}}=647 \mathrm{~cm}, \mathrm{~N}_{\mathrm{d}}=5.7 \times 10^{14}$ deuterons, $\mathrm{n}_{\mathrm{H}}=6.6 \times 10^{22} \mathrm{H}$ atcms $/ \mathrm{cm}^{3}, \Omega=2.0 \times 10^{-3}$ steradians, and $\mathrm{V}=$ $176.3 \mathrm{~cm}^{3}$. Values of the energy dependent terrns $\varepsilon_{2}\left(T^{t}\right), \frac{d \sigma}{d \Omega}(T, \theta)$, and $G(T, \theta)$ are listed in table VI for neutron energles from 10 to 70 MeV. The detertilnation of these energy dependent terms has been described previousiy by Madey and Waterman (1973).

\section{Results}

The absolute neutron spectra deterniryed from one- and twoparameter analys1s of the data are plotted in Fig. 10. For clarity, error bars destenating the statist1cal uncertatnty in the measurement are shown for the one-parameter analysis only. Since each spectrum contains the same number of events, the statistical uncertainty of the two-parauter measurement is equivalent to that of the one-parameter measurement. Except for the fact that the peak appears to be somewhat sharper in the one-parameter analysis, the one- and two-parameter analysis of the data are in good agreenent. In each case, the neutron spectrum exhibits an approxdmately symmetric peak at about $31 \mathrm{MeV}$ with a full-width at half-maximm of about $20 \mathrm{MeV}$. The agreement of the spectra obtained by the one- and two-paraneter analysis techniques confirms the princlple of the two-parameter spectrometer. 
Values of the energy dependent terms $\varepsilon_{2}\left(T^{1}\right), \frac{d \sigma}{d \Omega}(T, \theta)$ and $G(T, \theta)$ for incident neutron energies from 10 to $70 \mathrm{MeV}$.

Neutron Ehergy,

\begin{tabular}{|c|c|c|c|}
\hline$I(\mathrm{MeV})$ & $\varepsilon_{2}\left(T^{+}\right) \quad(\%)$ & $\frac{\mathrm{d}}{\alpha \hat{\alpha}}(\mathrm{T}, \theta)(\mathrm{mb} / \mathrm{sr})$ & $Q(T, \theta)(\tilde{F})$ \\
\hline 10 & 16.1 & 268 & 49.5 \\
\hline 20 & 16.5 & 137 & 56.9 \\
\hline 30 & 15.3 & 83.1 & 62.7 \\
\hline 40 & 14.4 & 56.5 & 68.4 \\
\hline 50 & 14.8 & 41.7 & 72.9 \\
\hline 60 & 15.2 & 32.4 & 76.4 \\
\hline 70 & 15.1 & 26.3 & 79.2 \\
\hline
\end{tabular}




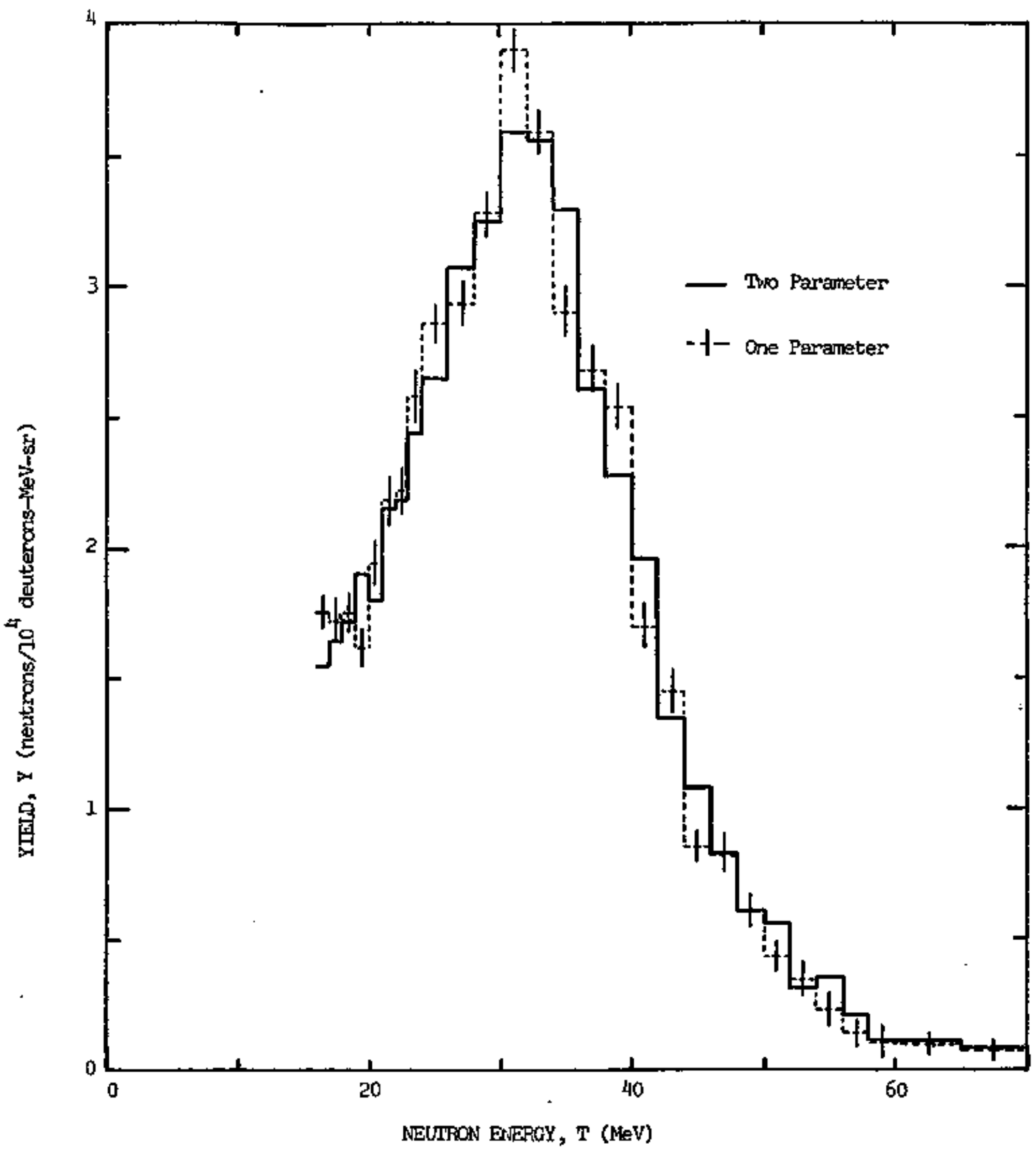

FIG. 10. Neutron spectrum at $0^{\circ}$ from $71-\mathrm{NeV}$ deuteron bombardment of a thick carbon target analyzed by one- and two- parameter techuliques. 


\section{References}

GARLTCK, G. F.

1952: and G. T. Wricht, Proceedings of the Physical Society (London), 65B, 415 .

GOODING, T. J.

1960: and H. G. Pugh, Mucl. Instr. and Meth. 7, 189.

3961: and H. (G. Pugh, Wucl. Instr. and Meth. 11, 365.

MADEY, R.

1972: and F. K. Wateman, The Fesporise of NE-228 Liquid Scintillator to $3.5,5.8$, and $10.5 \mathrm{meV}$ Protons, Nucl. Instr. and Meth. 204, 253.

1973: and F. M. Waterman, A TMe-of-Flight Spectroneter for Neutrons from 1 to $500 \mathrm{kgV}$, Nucl. Instr. and Meth. 106, 89 . 
Appendix B

Development of the Tho-Parameter Spectrometer 
Appenotix B

Deve lopment of the Two-Parameter Spectrometer

\section{Introduction}

As described In Appendix A, the principle of the two-paraneter measurement technique was conf'lnmed experimentally by a spectral measurement at the University of Maryland in July 1973. Development of the spectrometer since that time has proceeded along two lines: the development of a linear gate and stretcher with a large dymamic range, and the development of large detector's for neutron skyshine measurements. In Section 2, we describe the large first detectors for neutron skyshine measurements. In Section 3, we describe the jmproved Hnear gate and stretcher.

\section{Descriotion of Large First Detectors for Slyshine Heasurements}

Distenfeld (1973) estimates that the flux densities of skyshine neutrons vary with the locations selected outside the shield from about 0.1 to 1 and perhaps up to 5 neutrons/ $\mathrm{cm}^{2}$-sec. To obtain a practical count rate in a low-flux envirownent, it is necessary to improve the spectrometer efflclency by using langer first detectors. Wh1le increasing the detector dimensions enhances the count rate, It degrades also the energy resolution of the spectrometer; therefore, the detector dimensions represent a compromise between count rate and energy resolution. Consideration must also be given to the relationship between neutron atteruation and the thickoss of the first detector. The mean free-path for nuclear interactions of $10 \mathrm{HeV}$ incident neutrons $1 \mathrm{~s} 9.7 \mathrm{~cm}$ in $\mathrm{kE}-102$ plastic scintillator and 
.10 .13 in in $\mathrm{AE}-228$ Ifquid scint1liator. For spectral measurements down to $10 \mathrm{MeV}$, the first detector thickness should not exceed about $10 \mathrm{~cm}$ to avoid severe neutron attenuation.

Besed on the above considerations, the dimensions of the first detector were selected to be $10 \mathrm{in}$. by $10 . \mathrm{in}$. by $4 \mathrm{in.} \mathrm{thick.} \mathrm{In}$ Appendix A of our renewal proposal for the perlod from 1 September 1974 to August 31, 1975, we show that when used In conjunction with the 91 . diam by 8 in. thick second detector and a 1.5 meter flightpath, a $10 \mathrm{in}$. by $10 \mathrm{1n}$. by $4 \mathrm{in}$. NE-102 rirst detector will give a count rate of about 2 counts per minute for an incident neutron fux density of $0.1 \mathrm{n} / \mathrm{cm}^{2}-$ sec above $10 \mathrm{MeV}$.

Lange area first detectors also have the advantage of reducing edge effects caused by energetic recoll-protons that escape the first detector. Madey and Waterman (1974) have presented a graph of the included angle between the recoll proton and scattered neutron in the first detector for neutron energies upton $1 \mathrm{GeV}$. This included angle is about $90^{\circ}$ indeperxient of the energy of the incident neutron. Since neutrons that scatter from the first detector into the second detector are drected parallel to the spectroneter axis, the secoil-protons are always directed approximately perpend1cular to the spectroneter axis; hence, the larger the lateral dimensions of the first detector, the smaller will be the percentage of recoll-protons that have sufficient range to escape the first detector.

Figure 1 is a sketch of a $10 \mathrm{In}$. by $10 \mathrm{in}$. by $4 \mathrm{In}$. thick NE-102 plastic scintillator procured from Nuclear Enterprises Inc! As

WNuclear Enterprises, Inc., 935 Terminal Way, San Carlos; Caltformia 94070. 

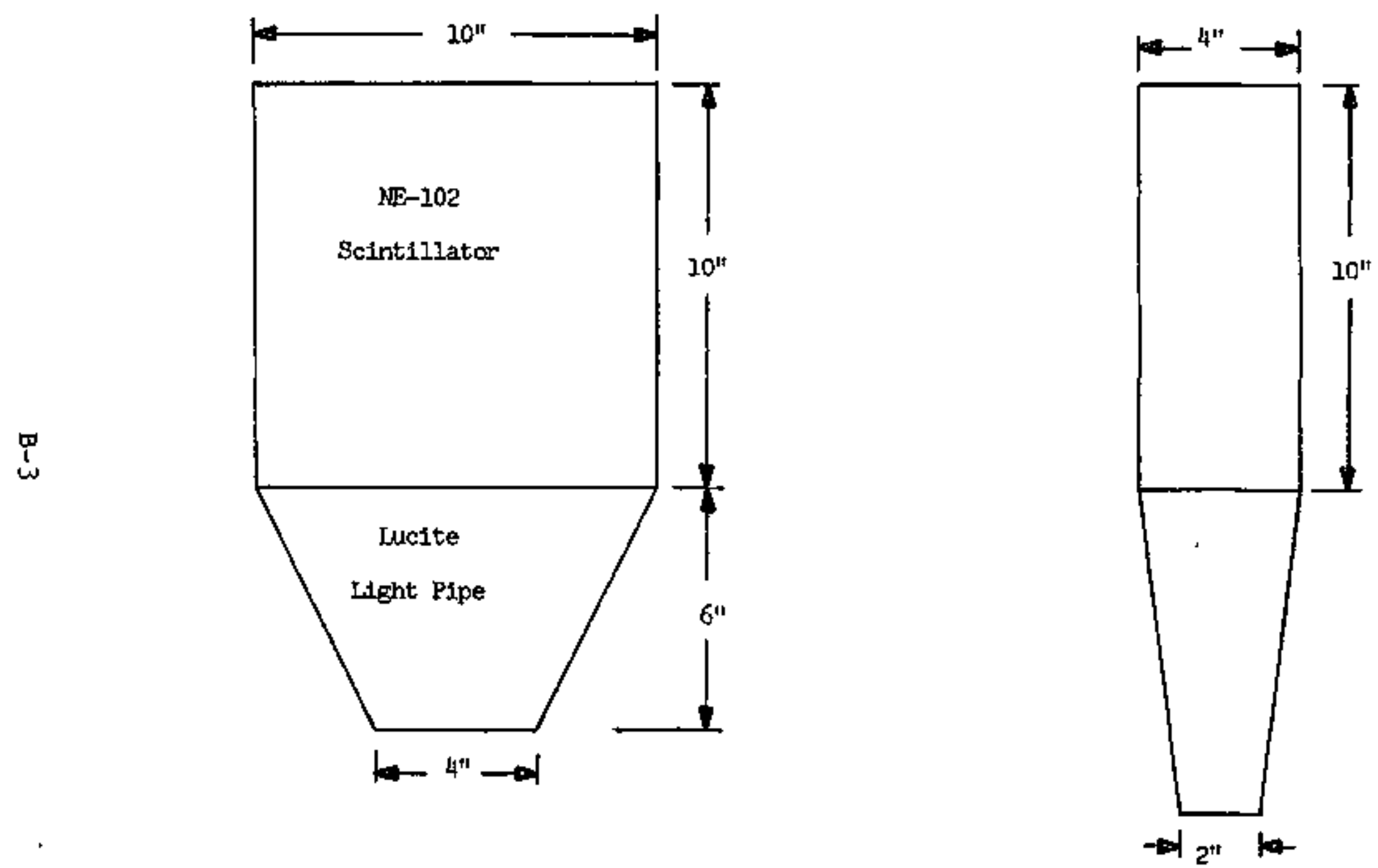

FIG, 1 Sketch of the $10 \mathrm{1n}$. by $10 \mathrm{in}$, by $4 \mathrm{nn}$. NE-102 plastic scintillator and tapered 1 lucite light pipe. 
shown in FIg. 1, the scintillator is bonded to a lucite light pipe that tapers from a $10 \mathrm{fn}$. by $4 \mathrm{fn}$. cross section to a $4 \mathrm{fn}$. by $2 \mathrm{in}$. cross section over a height of 6 inches. Figure 2 is a plot of Fn-54, Na-22, and Th-228 Compton spectra messured w1th the 101 n. by $10 \mathrm{in}$. by 4 in. thick $\mathrm{NE}-102$ scintillator. The spectra shown in Flg. 2 were recorded whth the scintillator mounted on an Arperex 58 AVP photomultiplier operated at $1.8 \mathrm{kv}$. Below, we list the radfoactive ganma-ray energy, the equivalent-electron energy $\mathrm{T}_{e}$ of the Compton peak, and the pulse-height resolution $\Delta \mathrm{T}_{\mathrm{e}} / \mathrm{T}_{\mathrm{e}}$ in electron energy for each of the Compton spectra shown in Fig. 2.

\begin{tabular}{|c|c|c|c|}
\hline $\begin{array}{l}\text { Radioactive } \\
\text { Nuclide }\end{array}$ & $\begin{array}{l}\text { Garma } \\
\text { Energy } \\
T_{\gamma}\left(H^{*}=V\right)\end{array}$ & $\begin{array}{l}\text { Equivalent-Electron } \\
\text { Erergy; } T_{e} \text { (MeV) }\end{array}$ & $\begin{array}{l}\text { Pulse-Helght } \\
\text { Resolution, } \Delta \mathrm{T}_{\mathrm{e}} / \mathrm{T}_{\mathrm{e}}^{(\%)}\end{array}$ \\
\hline$m n-54$ & 0.84 & 0.64 & 36 \\
\hline $\mathrm{Na}-22$ & 1.28 & 1.06 & 27 \\
\hline Th-228 & 2.62 & 2.39 & 20 \\
\hline
\end{tabular}

Comparison of the above values of the pulse-height resolution with those Hsted in Table III in Append1x $A$ for the $2 \frac{1}{2} \mathbf{~ n}$, diam by $2 \frac{1}{2} 1$. high $\mathrm{NE}-102$ scintillator show that the pulse-height resolution of the much larger $10 \mathrm{in}$. by $10 \mathrm{fn}$. by $4 \mathrm{in}$. NE-102 sctntillator is only about a factor of 2 poorer than that of the $2 \frac{1}{2}$ In. diam by $21_{2} 1$. high scintillator. The $10 \mathrm{ln}$. by $10 \mathrm{ln}$. by $4 \mathrm{in.} \mathrm{ME}-102$ sefntillator was tested recently in a spectral measurement at the University of Maryland. These data are currently be1ng analyzed. 


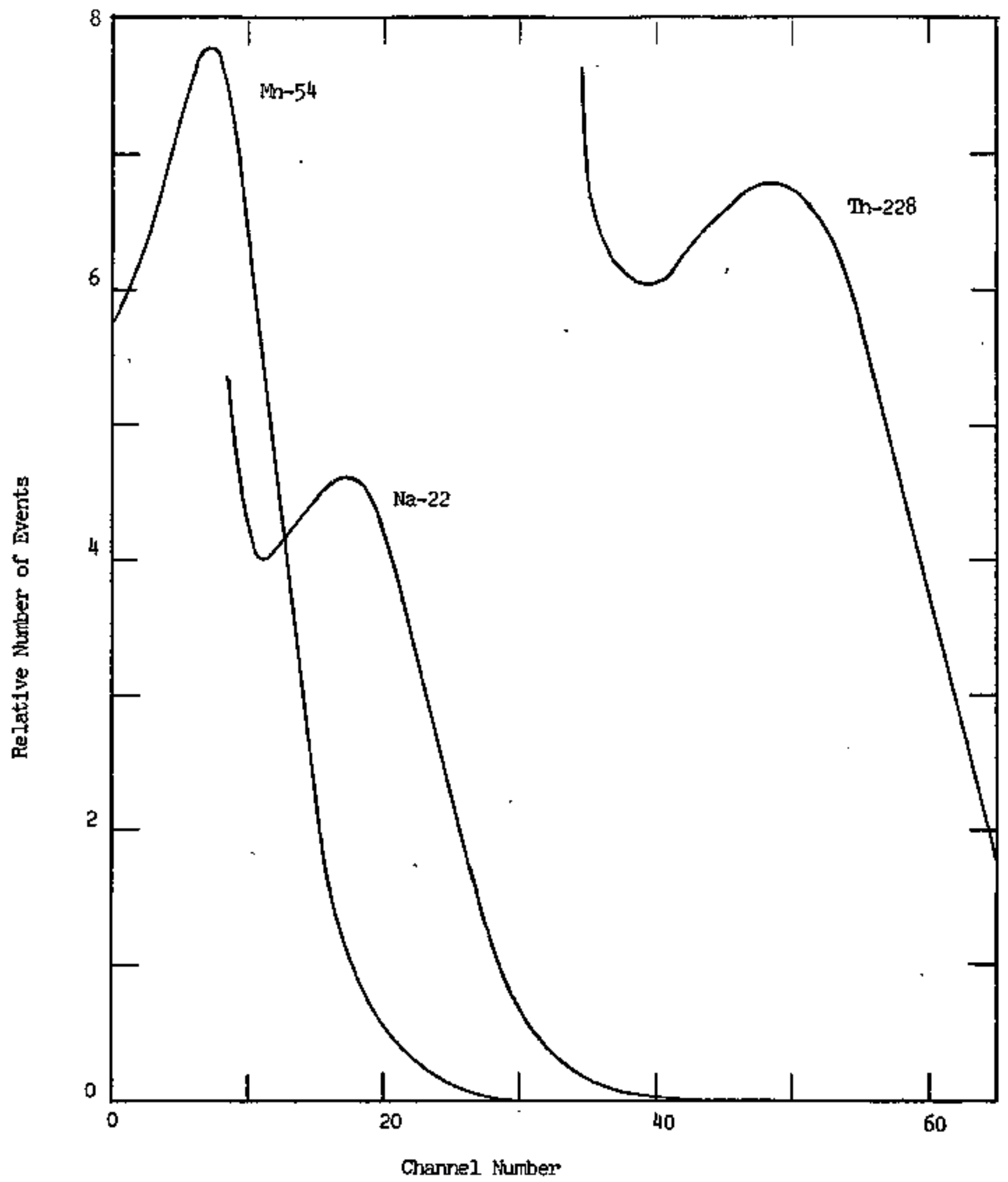

FIG. 2 The Compton spectra of 1 Tr-54, Na-22, and Th-228 garme-ray sources ohserved with the $10 \mathrm{in}$. by $10 \mathrm{In}$. by $4 \mathrm{In}$. NE-102 plastic scintillator.

$$
B-5
$$


After encountering long delays in procuring a 10 in. by 10 in. by 4 in. NE-228 liquid scintillator, we decided to construct the detector at Kent State Untversity. Floure 3 is a sketch of the aluminum chamber constructed to encapsulate the liquid scintillator. The l1ght outpust of NE-228 jiquid scintillator is only about $70 \%$ that of NE-102 plastic scintillator. In an effort to improve the pulse-hefght resolution of the ME-228 detector, the aluminum cell was designed so that the photomultiplier is in direct contact with the liquid scintillator. Th1s design reduces the number of Interfaces between the scintillator and photomultiplier and elfintates light attenuation that would occur in a itght plpe. To optinize the light collection, the interior of the aluminzom chamber was pafited with white reflector paint. The 10 in. by $10 \mathrm{in}$. sides of the chamber are constructed of 1/8-inch thick alimilnum; the $10 \mathrm{In}$. by $\mathrm{H}$ in. sides of 1/4-inch thick aluntnum; and the $10 \mathrm{in}$. by 4 In. ends of tainch thick aluminusn. A 3 in. diam by $1 \mathrm{in}$. hitg cylindrical chamber serves as an expansion chamber. The performance of this detector has not yet been tested. 

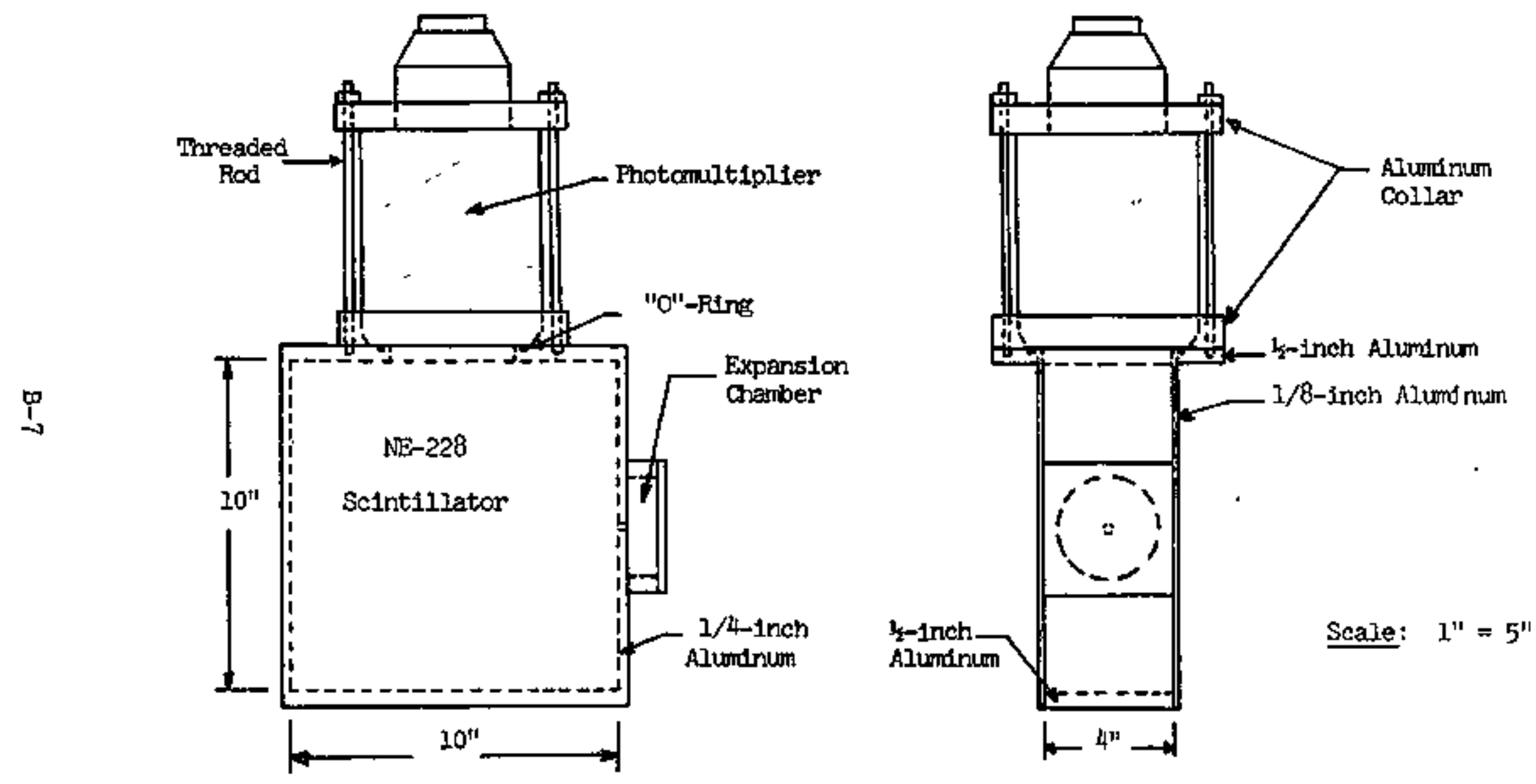

FIG. 3 Sketch of the construction of the $10 \mathrm{in.}$ by $10 \mathrm{in}$. by $4 \mathrm{in}$. NE-228 scintiliator counter. 


\section{A Linear Gate and Stretcher with a Large Dynamic Pange}

Conmercially avaslable linear gate and stretchers do not have an adequate dynanlic range to measure the recoll-proton pulse-helght spectsum in a spectral measurement of onidirectiomal neutrons from a few $\mathrm{MeV}$ to about $150 \mathrm{MeV}$. In such a measurement, the dymamic range of recoll-proton pulse-heights is expected to be about 170 to 1 . In this section, we describe a linear gate and stretcher that has been designed and constructed for photomultiplier anode pulses from 25 m1llivolts to 15 volts, thus giving a potential dynamic range of 600 to 1 .

The circult of the linear gate and stretcher module is divided into four separate circults: two gate and stretcher cards, a selector card, and an amplifier card. The circust first converts the Input pulse voltage to a current pulse. The current pulse amplitude will be linited by the circult if the current exceeds a preset maximum value. The current pulse is then gated by a diote gate and linearly integrated by a low capactince stretching capactior. Two gate and stretcher cards are used to achreve a potential dynanic range of 600 to 1 . The first card is designed for operation with input voltages from 25 millivolts to 1 volt; the second from 0.5 volt to 15 volts. The stretcher cards are linear to within $\pm 1 \%$ over their respective regions. The selector card monitors the pulse-heights of the gate and stretcher cards and determines when to switch from the low level (25 milltuolt 
to 1 volt) output signal to the high level (0.5 volt to 15 volts) output signal. This selection is accomplished by a Schmitt trigger voltage discriminator which monitors the low Ievel signal and switches to the high level signal at a speclfyed voltage level. The output level of each card is matched so that the difference in gain between the two channels is less than $1 \%$, providyng a linear response over a dynamse range of input pulse helghts of 600 to 1 . The output amplifier card provides fixed gatns of $1,2,4,8$, and 16 with an output inpedence of 10 ohns. The linear gate and stretcher output slgnal is sultable for direct connection to the Input of an anglog-to-digital converter.

\section{References}

DLSTWMEZD, c.

1973: Private cormunication to Rdchard Inadey.

MADEY, R.

1974: and F. M. Waterman, A Time-of-Flight Spectrometer for Neutrons from about $150 \mathrm{MeV}$ to I GeV, ihucl. Instr. and Weth. 114, 483. 
Appenaix C

The or-Line Data Acouisition Syster 


\section{Appendix C}

\section{The On-Line Data Acquisition Systen}

The transportable on-line data acquisition system ${ }^{\dagger}$ is a computerbased system for data acquistition, display, and mentpulation based on the Digital Equipment Corporations (DEC) PDP 11 computer. Peripheral modules are added to the system to perform the required functions. The ULLBUS hardware structure of the PDP-il provides a standardized data exchange path between all system corponents. This URLBUS feature permits expansion with a minimm of effort and allows the user to build the systern to almost any level of sophistication.

At present, the data acquisition system contalns the following major subsystems :
a. PDP $11 / 15$ Central Processing thit (CPU)
b. Core Mernory
c. Teletypewriter
d. System Control Panel
e. Nuclear Data Inputs
f. Display Unit
g. Magnet1c Tape Un1t

These subsysterns are show in Fig. 1 connected to the URIBUS data path. The PDP $11 / 15$ CPU is the operational center of the system. The

t Tennecorn Systems TP-5000 


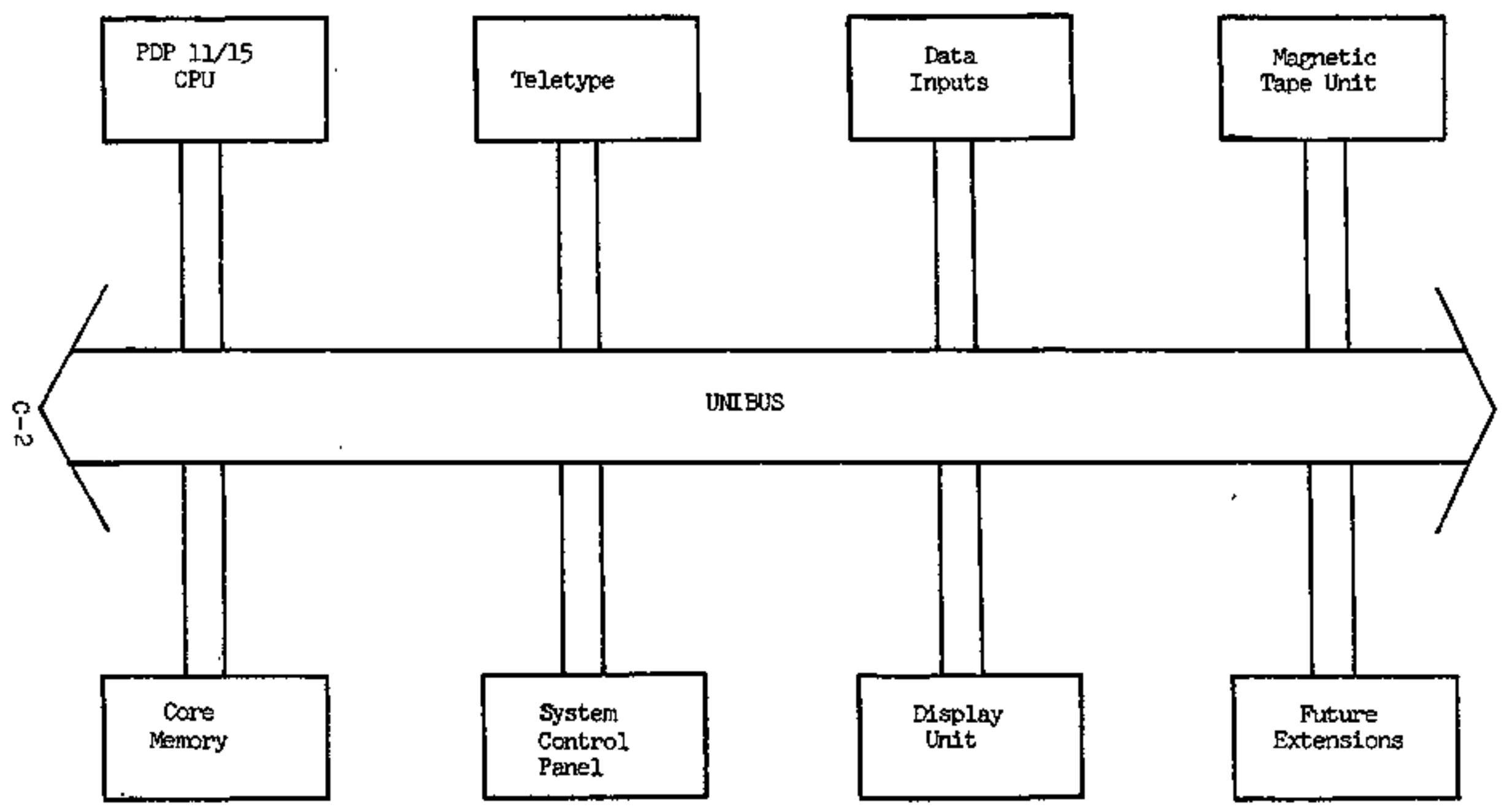

Fig. I Schematic diagram of the on-11ne data acquisition system. 
CPU provides decision making, data manipulation, and the interfacing between the remaining subsystems. The system contadns 24 thousand 16 bit words of core memory used to store date and operate prograns. The teletypewriter provides a convenient-path for transferring data between the user and the computer system. The system control panel provides a compact arrangement of knobs, switches, and buttons to operate the pulse-height analyzer system and to control the display unit, the nuclear data inputs, the magnetic tape unit, and other user defined operations. The nuclear data inputs are 4 analog to digital converters (ADC's). These ADC's may be used separately to record 4 single parameter spectra sinultaneously or in conbinations to record 2, 3, or 4 paraneter spectra. The display unit provides a visual view of the data being orocessed by the systen. A light pen permits the user to literact with the system. The tape urit provides a means of storing large anounts of data and the system programs. A stngle tape can store hundreds of tines more data than the core memory.

The data acquisition system may be disassembled into four sections for shlpping. Below, we list the weight of each of these sections. 


\section{Section}

a. Teletypewriter

b. Nagnetic Tape Unit

c. Central Frocessor and Menory Unit

d. Display, Control Panel and Data Input lelegt (lbs.)

50

150

150

300

Items $c$ and $d$ abowe may be broken down in to maller packages less than 50 pounds in welght. The power requirement of the data acquisition system is 15 anperes at 120 volts A.C. or 1.8 k1lowatts. " The floor space required for the data acquistition system and operator is about $8 \mathrm{ft}$. by $8 \mathrm{ft}$. . The system is $5 \mathrm{ft}$. high.

t The power requirement of the data acquisition system plus the electronic apparatus of the spectrometer is 3.6 kllowatts. 
Appendix D

Test of the Two-Parameter Spectrometer 
Appendix D

Measurement of a Simulated Omidirectional Neutron Spectrum with the

\section{Two-Parameter Spectrometer.}

In liarch 1974, we tested the ability of the two-parameter spectrometer to measure the spectmm of neutrons incident omidirectionally on the spectrometer. For this test, we used a collimated bean of neutrons produced at $0^{\circ}$ from $82 \mathrm{NeV}$ deuteron bombardment of a thick beryllifu target at the University of Naryland cyclotron. To simulate a spectral measurement of ondidirectional neturons, measurements were made with the neutron beam incident on the spectrometer at angles of $20 \% 49^{\circ}$ and $75^{\circ}$. The experimental arrangement for each of these measurements is shown schemat1cally in Fiss, 1 (a), (b), and (c). Only the spectrometer orlentation with respect to the neutron beam was changed; all other parameters remained the same. Since the neutron beam incident on the spectrometer at angles of $20^{\circ} 45^{\circ}$ and $70^{\circ}$ was the same, the final spectrun obtatned from each measurement should also be the same even though the range of the recoil-proton and scattered neutron energles in each measurement are slgniflcantly different; for example, a $50 \mathrm{MeV}$ neutron incident at an angle of $20^{\circ}$ produces a $6 \mathrm{MeV}$ recoli-proton, whereas a $50 \mathrm{MeV}$ neutron incident at $70^{\circ}$ produces a $44 \mathrm{MeV}$ recoilproton. Figure 2 is a trace of the one-dimensional time-of-fight spectra obtained with the neutron beam incident at angles of $20^{\circ}$, 45, and $70^{\circ}$. The different spectral shape obtained for each meastmement reflects the different range of scattered neutron energies present. 


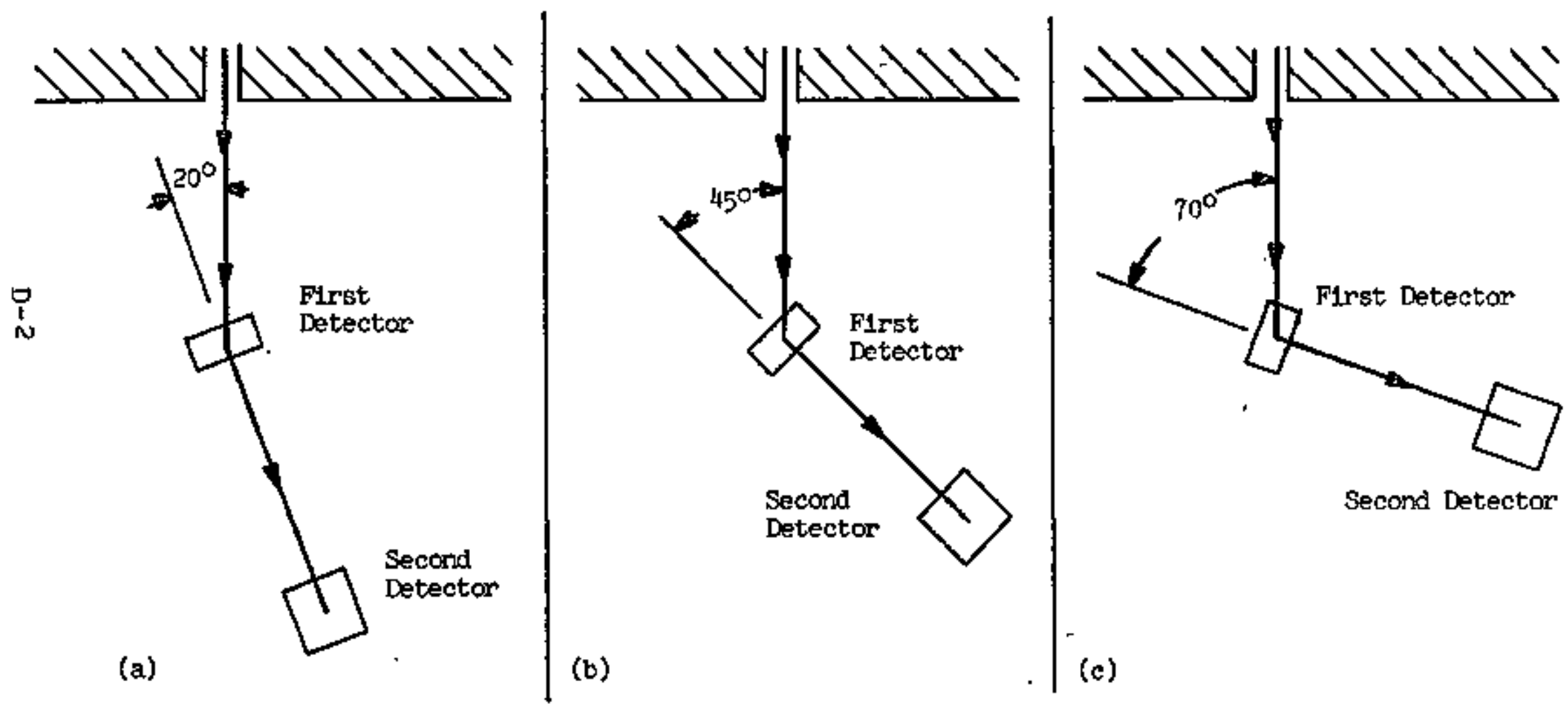

FIG. 1. The expertmental arrangement used at the University of Maryland cyclotron to simulate an cmidirectional spectral measurement. Spectral measurement were made with the neutron bean incident on the spectrometer at angles of (a) $20^{\circ}$, (b) $45^{\circ}$, and (c) $70^{\circ}$. 


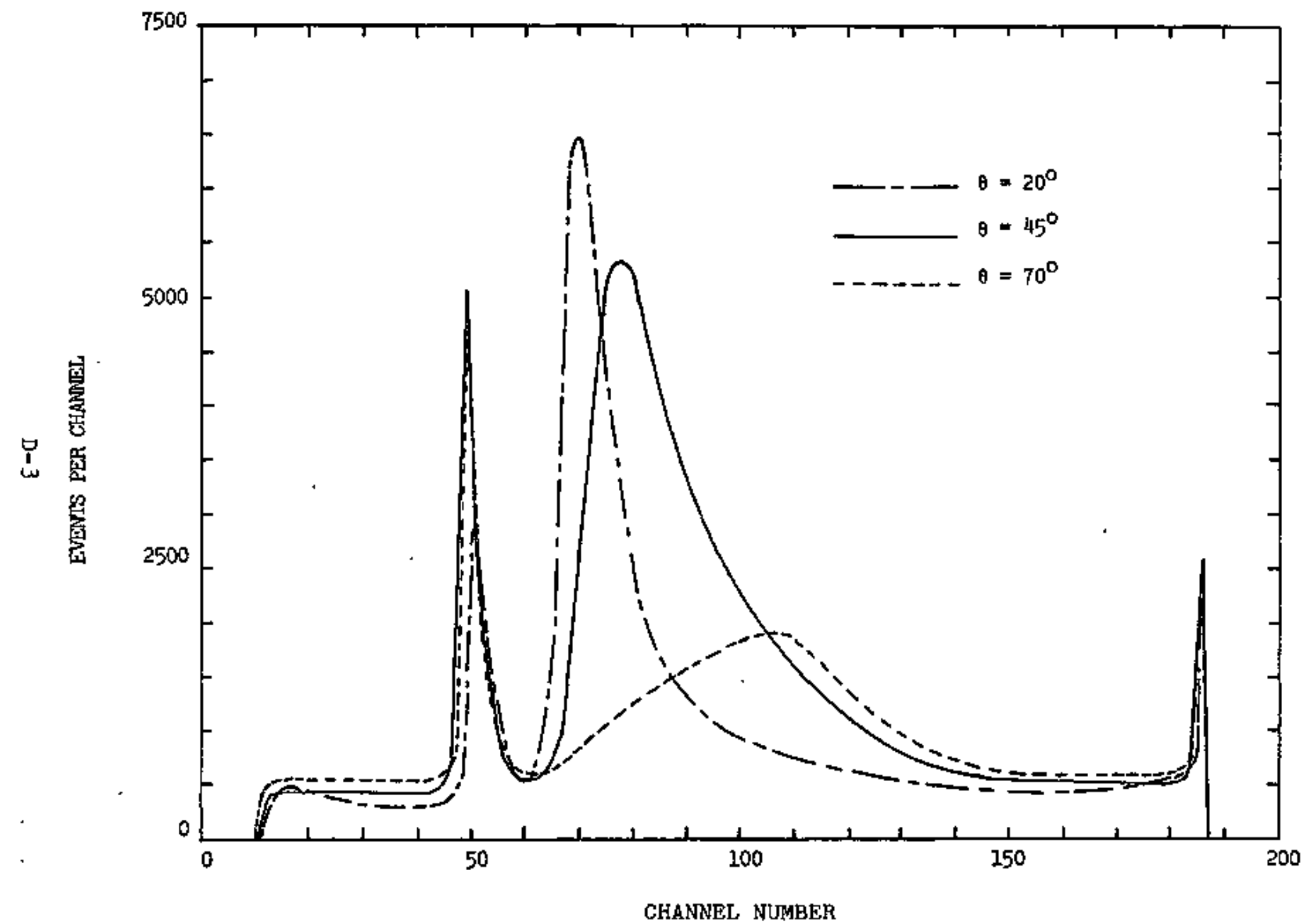

FIĢ. 2. One-parameter neutron time-or-flight spectra recorded with the neutron bean incident on the spectrometer at angles of 20,45 , and $75^{\circ}$. 
The fact that each measurement must give the same final result provides a severe test of the system and of the ablilty to correct for the energy and angular dependence of the spectrometer efficiency. These data are currently being aralyzed.

$$
\text { D- } 4
$$

